\title{
Protección del medio ambiente en el contexto de una nueva constitución: recomendaciones en base a la experiencia comparada
}

\author{
Environmental Protection in the Context of a New Constitution: Suggestions \\ Considering the Experience of other Countries
}

\author{
Gustavo ARELlano ReYes 1 \\ Federico GUARACHI ZuVIC ${ }^{2}$
}

\begin{abstract}
Resumen: En el contexto de discusión de una nueva Constitución Política para Chile, la protección del medio ambiente necesariamente debe ser parte del debate constituyente. De esta manera, este trabajo, con el propósito de entregar herramientas para esta discusión, realiza un análisis crítico respecto a la forma en que la Constitución Política de 1980 aborda la protección del medioambiente y analiza la experiencia comparada en esta materia, destacando la labor de distintos países para consagrar la protección del medio ambiente en sus constituciones. Finalmente, se realizan recomendaciones sobre las temáticas que debiese considerar una constitución en materia ambiental.
\end{abstract}

Palabras clave: Medio ambiente, medio ambiente libre de contaminación, derecho ambiental, derecho constitucional ambiental

\begin{abstract}
In the discussion of a new Constitution for Chile, the protection of the environment must be part of the constitutional debate. In the aims of providing tools for this discussion, this paper does a critical analysis of the way the 1980's Constitution regulates the protection of the environment and studies the experience of other countries, highlighting the work of different nations in the protection of the environment. Lastly, it states a few suggestions about the topics related with this subject that should be considered in a new constitution.
\end{abstract}

\footnotetext{
${ }^{1}$ Abogado Universidad de Chile, especializado en derecho ambiental y administrativo, actualmente abogado de la Fiscalía de la Superintendencia del Medio Ambiente, ciudad de Santiago Chile. Correo electrónico: gustavoarellanoreyes@gmail.com

${ }^{2}$ Abogado Universidad de Chile, especializado en derecho ambiental y administrativo, actualmente investigador en la Dirección de Estudios de la Corte Suprema, ciudad de Santiago, Chile. Correo electrónico: fguarachi@gmail.com
} 
Keywords: Environment, Healthy Environment, Environmental Law, Constitutional Environmental Law

\section{Introducción}

La actual Constitución Política de la República de Chile (en adelante, CPR), vigente desde el año 1980 y modificada en forma no sustancial a la fecha, ha sido objeto de especial cuestionamiento durante el estallido social vivido en nuestro país a partir del mes de octubre del año 2019. Lo anterior, encuentra sustento en los vicios de legitimidad que posee la CPR por no tener un origen democrático, y por establecer un modelo que a casi 40 años de su instauración ha demostrado ser insuficiente para proteger debidamente al medio ambiente, implantando un sistema económico que promueve un uso abusivo de los recursos naturales y un deterioro considerable de los ecosistemas.

El Capítulo III de la CPR, referido a los derechos y deberes constitucionales, establece en su artículo 19 №8 el derecho a vivir en un medio ambiente libre de contaminación, señalando que es deber del Estado velar para que este derecho no sea afectado y tutelar la preservación de la naturaleza. La referida garantía ha sido objeto de debate y críticas desde su génesis, destacando dentro de ellas: la discusión sobre la ubicación de este derecho dentro de la constitución; que su texto se centra en el ser humano y no en el medio ambiente como objeto de protección per se; que la acción de tutela asociada a este derecho requiere de mayores requisitos que respecto de las demás garantías listadas en el artículo 19; entre otras.

Considerando que se realizará un plebiscito nacional que tendrá como objeto definir si se dará inicio a un proceso de asamblea constituyente y entendiendo que una constitución es "un acto de afirmación política que define un "nosotros" y da a ese nosotros una determinada forma política, es decir un modo de acción (una manera de determinar qué es lo que esa unidad política quiere o hace)”3, es que nos planteamos cómo sería posible fortalecer la protección del medio ambiente, sobre la base las dificultades que se han observado en la aplicación de esta normativa (artículo 19 №8 CPR) desde que se encuentra vigente y la experiencia comparada asociada a los textos constitucionales de otros países.

Para dar respuesta a la interrogante planteada: se revisarán las discusiones que se han generado respecto de la redacción de la garantía constitucional indicada, considerando

${ }^{3}$ Atria (2015), p. 35. 
especialmente aspectos doctrinarios y jurisprudenciales; posteriormente se examinará los textos constitucionales de 4 países que representan características relevantes y similares a la realidad de Chile, sobre la base de criterios de análisis, que fueron construidos luego del estudio de las discusiones suscitadas con motivo de la actual redacción del texto constitucional; para finalmente esbozar como conclusión, sugerencias y/o recomendaciones para el debate que se desarrollara durante el proceso constituyente que se avecina para Chile ${ }^{4}$.

\section{El Medio Ambiente en la Constitución Política de 1980}

La protección del medio ambiente se encuentra consagrada en la CPR, específicamente en su artículo 19 №8, el cual establece como una garantía "El derecho a vivir en un medio ambiente libre de contaminación. Es deber del Estado velar para que este derecho no sea afectado y tutelar la preservación de la naturaleza". Luego en el inciso segundo de esta norma señala que "La ley podrá establecer restricciones específicas al ejercicio de determinados derechos o libertades para proteger el medio ambiente".

La redacción de esta garantía constitucional ha suscitado diversas discusiones respecto de distintos aspectos, por lo que a continuación, se realizará un análisis descriptivo y resumido de las principales discusiones que ha provocado la redacción de esta norma, en cuanto: (a) el lugar de la CPR en el cual se encarga la protección del medio ambiente; (b) la titularidad de la acción que lo protege; (c) el concepto de contaminación; (d) la acción de protección; (e) la tutela de la preservación de la naturaleza.

\subsection{UBICACIÓN DE LA PROTECCIÓN DEL MEDIO AMBIENTE EN LA CONSTITUCIÓN DE 1980}

Durante la discusión de la CPR en la Comisión Ortuzar, se analizó si la protección del medio ambiente debía ir en el capítulo I "Bases de la institucionalidad", o solo como un derecho fundamental en el catálogo de derechos incluidos en el artículo 19. En esta línea, el comisionado Silva Bascuñán introduce la discusión señalando

De manera que esa disposición debe estar en el capítulo de las normas generales, precisamente porque expresa el ideal básico de la Constitución, que debe subrayar, dentro de la idea general de bien común y dados los tiempos históricos que se viven, ese aspecto tan importante, como integrante nuevo, bastante configurado, propio y necesario, del bien común ${ }^{5}$.

\footnotetext{
${ }^{4}$ Temáticas como el agua y los pueblos originarios fueron excluidas del examen del presente estudio, debido a que por su extensión estimamos que requieren de un análisis particular.

${ }^{5}$ Actas de la Comisión Ortuzar (1976).
} 
Esta propuesta fue desechada por el resto de la comisión ${ }^{6}$, al expresarse por el comisionado Ortuzar

[...] está bien consagrar en esta parte la garantía constitucional relativa al medio ambiente. En primer término, la observación formulada por el señor Silva Bascuñán en el sentido de que en cierto modo el medio ambiente está comprendido en el bien común, que es deber del Estado promover, constituye precisamente una razón para no establecerlo en el capítulo I, porque se estaría, en cierta forma, reiterando un concepto ${ }^{7}$.

En este orden de ideas, podemos observar, que se prefirió por un modelo en el cual se consagra para las personas un derecho a vivir en un medio ambiente libre de contaminación, por sobre uno que incluyera el medio ambiente dentro de las Bases de la Institucionalidad como un principio fundamental del concepto de bien común. Galdámez ha mencionado sobre este punto que

Del trabajo de la Comisión puede sostenerse, entonces, que para esos años se trató de priorizar la configuración de un derecho de carácter individual. La tensión entre este derecho y otros de la Constitución, quedó plasmada en el inciso segundo de la disposición que mandata al legislador a limitar otros derechos cuando es necesario proteger el medio ambiente ${ }^{8}$.

Esta discusión toma relevancia, al considerar que el primer capítulo de la CPR, además de definir los valores y principios que caracterizan a una nación, se utiliza para interpretar las diversas normas de la misma. En este sentido, se ha mencionado que:

Primeramente, los valores, principios y preceptos reunidos en este capítulo tienen la cualidad de cimiento o sustento sobre el cual se levanta todo el sistema institucional, como punto de partida de la convivencia civilizada de las personas, la familia, los grupos intermedios de la sociedad y del Estado en general. (...) Efectivamente, al momento de interpretar y aplicar la Carta Fundamental, siempre es y será imperativo tener en cuenta el capítulo I y, si algún valor, norma o principio de la Constitución está en contradicción con cierta disposición del capítulo entonces debe primar la de este último por su carácter de básico y fundamental9.

\subsection{EL DERECHO A VIVIR EN UN MEDIO AMBIENTE LIBRE DE CONTAMINACIÓN CENTRADO EN EL SER HUMANO}

Como se puede observar de la lectura del texto constitucional, el derecho consagrado se encuentra relacionado con el "vivir" en un medio ambiente libre de contaminación. Esta relación con el derecho a la vida, de acuerdo con Bermúdez tiene como consecuencia que

\footnotetext{
${ }^{6}$ En el mismo sentido, el comisionado Diez sostuvo que estaba "en desacuerdo con el señor Silva Bascuñán, porque, tal como el señor presidente, cree que éste es un derecho. Y, además, es un derecho de las personas individualmente consideradas; es un derecho individual a vivir en ambientes libres de contaminación, por lo que debe ser puesto entre los derechos".

${ }^{7}$ Actas de la Comisión Ortuzar (1976).

${ }^{8}$ Galdámez (2018), p. 80.

${ }^{9}$ Cea (2002), pp. 162-163.
} 
[...] las posibilidades de amparo judicial de este derecho requieren como presupuesto que exista una afectación en el derecho de una persona natural, no estando legitimados para recurrir quienes no tienen el derecho, por ejemplo, las personas jurídicas, que como tales podrían tener por finalidad la protección del medio ambiente, pero dado que éstas no son titulares del derecho, no podrían esgrimir un derecho subjetivo del medio ambiente ${ }^{10}$.

Sin embargo, este ha sido un aspecto discutido en la doctrina, así Ossandón señala:

La Constitución chilena no se pronuncia expresamente sobre el otorgamiento o denegación de titularidad de derechos fundamentales a las personas jurídicas. Por ello, los esfuerzos de dar o quitárselos vienen de la interpretación del texto constitucional. En el caso del derecho a vivir en un medio ambiente libre de contaminación existe doctrina en ambos sentidos, desde los que niegan la titularidad agrupando el derecho dentro de los que solo pueden ser ejercidos por personas naturales, interpretando el término vivir de forma idéntica al derecho a la vida del art. $19 \mathrm{~N}^{\circ} 1$, hasta los que aceptan la titularidad por que el encabezado del art. 19 no distingue, y donde el constituyente no ha distinguido le está vedado al intérprete hacerlo ${ }^{11}$.

Nuestra jurisprudencia se ha dividido en este punto, aceptando en ciertas ocasiones la legitimidad de personas jurídicas ${ }^{12}$, sosteniendo en un caso que:

En la especie no se divisan razones formales o sustantivas para concluir que las personas jurídicas de derecho privado y sin fines de lucro que comparecen en autos se encuentran impedidas de ejercer la acción constitucional de protección invocando la garantía del artículo 19 N ${ }^{\circ}$ de la Carta Fundamental, más aún si se considera que uno de los propósitos declarados de la Corporación y Fundación reclamantes es la protección y preservación del medio ambiente y, en particular, del Campo Dunar declarado Santuario de la Naturaleza a través de sucesivos decretos supremos desde 1993 a 2012, todo lo cual guarda armonía con el deber del Estado de garantizar la protección eficaz de este derecho fundamental ${ }^{13}$.

Por su parte, sobre este mismo punto, se ha establecido que

Cuando el artículo $19 \mathrm{~N}^{\circ} 8$ de la Constitución chilena se refiere al "derecho a vivir en un medio ambiente libre de contaminación", pone el acento, primeramente, en la vida de las personas, más que en el medio ambiente mismo. En este sentido, parte de la doctrina insiste en enfatizar que se trata de un derecho individual que protege a las personas, en la conservación de su vida ${ }^{14}$.

Bermúdez profundiza esta idea señalando:

En segundo término, debemos descartar que no procederá la invocación del derecho, con un afán meramente protector de la naturaleza en cuanto bien jurídico en sí mismo tutelado, bien jurídico que de acuerdo con el citado artículo 19 №8 corresponde al Estado resguardar ("Es deber del Estado... tutelar la preservación de la naturaleza"). Siempre la invocación deberá ser entendida

\footnotetext{
${ }^{10}$ Bermúdez (2014), p. 116.

11 Ossandón (2015), p. 136.

${ }^{12}$ Corte Suprema, Rol № 2463-2012, de 11 de mayo de 2012; Corte Suprema, Rol №3141-2012, de 15 de junio de 2012; Corte de Apelaciones de Valparaíso, Rol № 1670-2012, de 28 de marzo de 2013; Corte Suprema, Rol № 23.622/2014, de 26 de noviembre de 2014.

${ }^{13}$ Corte Suprema, Rol No 12.808-2019, de 5 de junio de 2019.

${ }^{14}$ Aguilar (2015), p.10-11.
} 
en relación con el derecho a vivir en un medio ambiente libre de contaminación, y no a un medio ambiente sin contaminar aisladamente considerado ${ }^{15}$.

En base a esta perspectiva, se ha sostenido además, que el derecho a vivir en un medio ambiente libre de contaminación es de carácter antropocéntrico, al afirmarse que

el medio ambiente no tendría una protección directa a través de la Constitución, si no que en relación con una persona que está "viviendo" en el (por ejemplo, a través de otros instrumentos, tales como el SEIA). En este sentido se podría sostener que la redacción del artículo 19non 8 es antropocéntrica ${ }^{16}$.

Este carácter, se encuentra en contraposición con la postura ecocéntrica o biocéntrica donde existe un

reconocimiento del valor inherente de todas las formas de vida. De este modo, la Naturaleza es sujeto de valores, sujeto de derechos. Y en este sentido, se debe avanzar en la discusión de una ética ambiental con relación a una ética social que propenda a una justicia ambiental y ecológica ${ }^{17}$.

Por otro lado, en base a la redacción del artículo 19 №8, y derivado del mismo punto anterior ha surgido la discusión de qué tipo de afectación se debe padecer para tener legitimación activa. En esta línea Bordalí ha expresado:

En cuanto a las sentencias recaídas en recursos de protección para la defensa del medio ambiente sano, la legitimación activa ha sido reconocida por la mayoría de dichos fallos, a aquellas personas, naturales y jurídicas, directamente afectadas en su derecho. (...) Esta posición, como ya apuntábamos, parece ser que deriva de considerar este derecho fundamental como ligado o íntimamente relacionado con el derecho a la vida y a la salud, bien este último que aparece como claramente divisible, y como tal, objeto de un derecho subjetivo de carácter individual ${ }^{18}$.

A pesar de que existen algunos autores como Künsemüller que consideran que hubo una voluntad explícita del constituyente de proteger el entorno en sí mismo como valor jurídico, la mayoría de la doctrina se encuentra conteste en la relación con el derecho a la vida, integridad física y psíquica y derecho a la protección de la salud (Bertelesen, Bordalí, Corral y Cea Egaña) ${ }^{19}$.

Nuestra jurisprudencia en reiteradas ocasiones ha invocado la afectación directa para declarar la procedencia del recurso de protección sosteniendo que

Sobre el particular, el recurrente de autos no describe y tampoco prueba en qué forma la garantía que invoca conculcada afecta su derecho a vivir en un medio ambiente libre de contaminación y,

\footnotetext{
${ }^{15}$ Bermúdez (2000), p. 11.

16 FIMA (2018), p.9.

${ }^{17}$ Gudynas (2016), p.684.

${ }^{18}$ Bordalí (1998), pp. 43.64.

${ }^{19}$ Aguilar (2016), p.374-375.
} 
no siendo esta acción cautelar de urgencia una acción popular, ello es de suyo suficiente para revocar la sentencia en alzada y rechazar consecuencialmente el recurso de protección ${ }^{20}$.

En la misma línea, en otra sentencia, se declaró que

Los recurrentes han invocado como derecho constitucional tutelado el consagrado en el $\mathrm{N}^{\circ} 8$ del artículo 19 de la Carta Fundamental, sin que hayan demostrado un interés directo e inmediato en la protección de la garantía que invocan, razón por la cual carecen de legitimación activa para interponer este recurso de protección ${ }^{21}$.

Así las cosas, nos encontramos frente a una norma que protege el medio ambiente sólo en base a su interacción con las personas, y no como un bien jurídico en sí mismo, lo cual a su vez tiene la consecuencia de limitar la titularidad de la acción a personas naturales, y a una afectación directa.

\subsection{EL CONCEPTO DE CONTAMINACIÓN}

En la Comisión Ortuzar, a la hora de discutir respecto del alcance del término contaminación y la posibilidad de cambiar este concepto, se señaló

que el Diccionario de la Real Academia de la Lengua dice lo siguiente respecto del verbo "contaminar": "alterar la pureza de alguna cosa, como los alimentos, las aguas, el aire, etcétera. 2. Penetrar la inmundicia un cuerpo, causando en él manchas y mal olor. 3. Contagiar, infeccionar...22.

En este sentido el término contaminación se podría interpretar en base a su definición de la RAE, considerando que ésta fue utilizada a la hora de discutir su redacción. No obstante, con la dictación de la Ley №19.300 sobre Bases Generales del Medio Ambiente (en adelante, LBGMA), se estableció un significado legal para este concepto, estipulando en su artículo $2^{\circ}$, letra c), que la contaminación corresponde a "la presencia en el ambiente de sustancias, elementos, energía o combinación de ellos, en concentraciones o concentraciones y permanencia superiores o inferiores, según corresponda, a las establecidas en la legislación vigente”.

A mayor abundamiento, la letra m) del mismo artículo establece el concepto de "medio ambiente libre de contaminación" como "aquél en el que los contaminantes se encuentran en concentraciones y períodos inferiores a aquéllos susceptibles de constituir un riesgo a la salud de las personas, a la calidad de vida de la población, a la preservación de la naturaleza o a la conservación del patrimonio ambiental".

${ }^{20}$ Corte Suprema, Rol N ${ }^{\circ} 45.059-2017$, de 13 de marzo de 2018.

${ }^{21}$ Corte Suprema, Rol N 7.677-2013, de 6 de enero de 2014.

${ }^{22}$ Actas de la Comisión Ortuzar (1976). 
En este sentido, el concepto de contaminación prescrito en nuestra legislación hace referencia a la superación de una norma, lo cual excluye diversos casos de contaminación que no se encuentran regulados actualmente por nuestro ordenamiento jurídico.

En esta línea se ha mencionado que:

Se identifican en este sentido, deficiencias en torno al término utilizado por el constituyente "medio ambiente libre de contaminación", que terminan por restringir aún más la tutela jurídica del $19 \mathrm{n}^{\circ} 8$. El hecho que se fijen los parámetros de qué debe entenderse por contaminación, o cuándo se está alterando el derecho al medio ambiente, exclusivamente desde la norma o desde una disposición legal, hace que se excluya una protección efectiva al derecho al medio ambiente, por ejemplo, al existir vacíos legales. (...) En la formulación actual se generan muchas dudas, por ejemplo, si se protege el medio ambiente libre de otros impactos, como son los daños ambientales u otras formas de alteración o riesgo del medio ambiente ${ }^{23}$.

Por su parte, el Tribunal Constitucional ha realizado una interpretación restrictiva de contaminación al sostener que:

Jurídicamente contaminación no es cualquier impacto o alteración ambiental sino la situación que supera los parámetros ambientales establecidos, y la norma que se ataca no contiene una autorización de tal índole. (...) De tal forma, mientras no se aprueben las normas de calidad ambiental respectivas que determinen objetivamente los parámetros dentro de los cuales es admisible en el ambiente una sustancia o elemento, no corresponde hablar de contaminación, a menos que se acredite inequívocamente la presencia en el ambiente de un contaminante, en términos tales que constituya un riesgo cierto a la vida, a la salud de la población, a la conservación del ambiente o la preservación de la naturaleza, o bien que exista una situación de pública e indiscutida notoriedad de la presencia gravemente nociva en el ambiente de un contaminante ${ }^{2425}$.

En el mismo sentido, en otra sentencia agrega que

Habiendo aceptando el constituyente que el medio ambiente es permanentemente modificado por la acción humana, la Ley $\mathrm{N}^{\circ} 19.300$, sobre bases generales del medio ambiente, concibe que la contaminación es un ilícito sólo cuando excede los niveles objetivos establecidos por la legislación, constituida especialmente por las normas de calidad ambiental y por las normas de emisión, a que se refiere este texto legislativo (artículo $2^{\circ}$, definiciones pertinentes) ${ }^{26}$.

De esta forma, se pueden observar casos en que para el sentido común puede existir un tipo de contaminación, pero que no obstante esta no se ajusta a la definición otorgada por nuestro ordenamiento jurídico. Aguilar ha ejemplificado esta situación al expresar:

Sin embargo, es posible imaginar otros casos de deterioro o degradación ambiental que no correspondan a episodios de contaminación estrictamente hablando, por ejemplo, la inundación de extensas zonas de terreno para la construcción de una represa, lo que alteraría el ecosistema

\footnotetext{
${ }^{23}$ FIMA (2018), p. 12.

24 Tribunal Constitucional, Rol № 577-06, de 26 de abril de 2007.

${ }^{25}$ En el mismo sentido: Tribunal Constitucional, Rol № 2643-14, de 27 de enero de 2015; Tribunal Constitucional, Rol № 1988-11, de 24 de junio de 2011;

${ }^{26}$ Tribunal Constitucional, Rol № 2684-14, de 10 de septiembre de abril de 2015.
} 
local, provocaría la migración o desaparición de especies, sumergiría un pueblo declarado patrimonio de la humanidad y dejaría bajo agua un cementerio indígena y, además, una zona ancestralmente usada por ciertas culturas como área de rituales sagrados ${ }^{27}$.

En este mismo orden, el criterio de Contraloría General de la República, al establecer que la alteración de áreas con valor patrimonial también puede generar deterioro o degradación al medio ambiente y que una interpretación contraria “... no se condice con la amplitud con que debe entenderse la garantía constitucional del artículo 19 №8 de la Constitución Política, ni con el contexto de la ley №19.300 y los demás cuerpos normativos sobre materias ambientales, que la desarrollan."28

Sin perjuicio de lo anterior, la jurisprudencia ha declarado procedentes recursos de protección entendiendo la contaminación desde una perspectiva más amplia al sostener

De acuerdo con los conceptos legales dados y conforme a los factores a que se refiere, se aprecia que la noción de contaminante es amplia y funcional y es la interpretación que mejor se adecua a la finalidad que procura dar reconocimiento efectivo al derecho constitucional a vivir en un medio ambiente libre de contaminación[... $]^{29}$.

En otra sentencia, se añadió que

nuestro país ha ratificado diversos instrumentos internacionales que abordan este particular y lo obligan a adoptar acciones de distinta clase con el objeto de tender a la restricción o a la eliminación, de diversos gases o compuestos químicos, incluso si éstos no se encuentran regulados en nuestro derecho interno por "una norma de emisión, plan de descontaminación u otra regulación vigente ${ }^{30}$.

Bajo este razonamiento, sin necesariamente desarrollar explícitamente el concepto de contaminación, la jurisprudencia ha acogido en diversas ocasiones el recurso de protección sin que medien mediciones incluso existiendo una norma de emisión debido a la falta de fiscalizaciones por la autoridad 31 , por no contar con los permisos o autorizaciones ambientales o sanitarias ${ }^{32}$, entre otros.

Así las cosas, nuestra constitución ha contemplado un concepto restringido de contaminación, el cual, sin embargo, ha sido interpretado por la jurisprudencia de nuestra Corte Suprema de una forma más amplia.

\footnotetext{
${ }^{27}$ Aguilar (2016), p. 375.

${ }^{28}$ Contraloría General de la República, Dictamen №4.000N16, de 15 de enero de 2016.

${ }^{29}$ Corte Suprema, Rol No 15.996-2013, de 31 de agosto de 2014.

${ }^{30}$ Corte de Apelaciones de Valparaíso, Rol No 5888-2019, de 28 de mayo de 2019.

${ }^{31}$ Corte Suprema, Rol ํ⒉515/2019, de 23 de mayo de 2019; Corte Suprema, Rol №5.473/2019, de 16 de abril de 2019; Corte Suprema, Rol N $11.845 / 2011$, de 22 de enero de 2012.

32 Corte Suprema, Rol N 4.690/2010, de 15 de agosto de 2010.
} 


\subsection{LA ACCIÓN DE PROTECCIÓN RESPECTO DEL DERECHO A VIVIR EN UN MEDIO AMBIENTE LIBRE DE CONTAMINACIÓN}

El artículo 20 de la $\mathrm{CPR}^{33}$, establece el recurso de protección, como una acción cautelar respecto de alguno de los derechos consagrados en el artículo 19. En particular, con relación a la garantía consagrada en el 19 №8 el inciso segundo del artículo 20 prescribe "Procederá, también, el recurso de protección en el caso del №8 del artículo 19, cuando el derecho a vivir en un medio ambiente libre de contaminación sea afectado por un acto u omisión ilegal imputable a una autoridad o persona determinada".

Al comparar el inciso primero con el inciso segundo del artículo 20 de la CPR se puede observar que la tutela de esta garantía es más limitada que las otras que se encuentran mencionadas en el artículo 20. Las principales diferencias corresponden al acto que puede estar sujeto a la acción de protección, la necesidad de imputabilidad del acto a una persona determinada y el concepto de afectación.

En cuanto al acto que puede ser objeto de la acción de protección, éste fue sujeto a reforma en el año 2005 cuando se cambió la frase "arbitrario e ilegal" por "acto u omisión ilegal". Al respecto, si se observa la historia de la Ley $\mathrm{N}^{\circ} 20.050$ que modificó la CPR, en la moción parlamentaria que dio inició a la discusión, solamente se buscaba sustituir la conjunción copulativa "e" por la conjunción disyuntiva "o", señalándose dentro de la discusión que

la exigencia conjunta de los requisitos de arbitrariedad e ilegalidad del acto de una autoridad o de un particular, ha significado en la práctica, la denegación de la protección constitucional del derecho a vivir en un medio ambiente libre de contaminación, por cuanto, en innumerables ocasiones, los recurridos han invocado la legalidad del acto o bien la no existencia de arbitrariedad, ante lo cual los tribunales han debido desechar los recursos ${ }^{34}$.

Sin perjuicio de lo anterior, en la discusión de la Comisión de Constitución y de Medio Ambiente unidas:

El H. Senador señor Viera-Gallo presentó una indicación para eliminar la expresión "arbitrario", de modo de mantener solamente la exigencia de que se trate de un acto ilegal para hacer

\footnotetext{
33 Constitución Política de la República. "Artículo 20. El que por causa de actos u omisiones arbitrarios o ilegales sufra privación, perturbación o amenaza en el legítimo ejercicio de los derechos y garantías establecidos en el artículo 19, números 1ำ $2^{\circ}, 3^{\circ}$ inciso

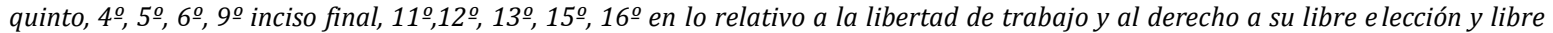
contratación, y a lo establecido en el inciso cuarto, $19^{\circ}, 21^{\circ}, 22^{\circ}, 23^{\circ}, 24^{\circ}$, y 25ำ podrá ocurrir por sí o por cualquiera a su nombre, a la Corte de Apelaciones respectiva, la que adoptará de inmediato las providencias que juzgue necesarias para restablecer el imperio del derecho y asegurar la debida protección del afectado, sin perjuicio de los demás derechos que pueda hacer valer ante la autoridad o los tribunales correspondientes.

Procederá, también, el recurso de protección en el caso del No8 del artículo 19, cuando el derecho a vivir en un medio ambien te libre de contaminación sea afectado por un acto u omisión ilegal imputable a una autoridad o persona determinada."

${ }^{34}$ Historia de la Ley $N^{\circ} 20.050$, p. 153. Disponible en https://bit.ly/3cKpgqp
} 
procedente el recurso (...) El H. Senador señor Fernández coincidió con la proposición anterior e hizo presente, una vez más, que la arbitrariedad bien puede entenderse incluida en la ilegalidad, por cuanto un acto arbitrario es, como lo destacó anteriormente, aquél "contrario a la justicia, la razón o las leyes, dictado sólo por la voluntad o el capricho". (...) No obstante, connotó que lo anterior podría entenderse como una nueva restricción a la procedencia del recurso en esta materia, al limitarlo sólo a las conductas que revisten caracteres de acto. Por ello planteó la conveniencia de incluir también las omisiones ilegales, que, en el caso de la protección del medio ambiente, pueden ser tan graves como las acciones ${ }^{35}$.

En cuanto a esta modificación se ha expresado que:

Lamentablemente, la reforma pudo haber sido mucho mejor, ello debido a que, si bien se suprimió el error desinformado de su improcedencia ante "omisiones", las cuales son "igualmente graves que las [acciones] en cuanto a los efectos dañinos al medio ambiente". Igualmente, existen voces disidentes a la "supresión de la arbitrariedad" como supuesto de la antijuridicidad copulativa con la ilegalidad de un Recurso de Protección Ambiental -también corregida por la judicatura-, debido a que se eliminaría la posibilidad de regular la discrecionalidad técnica ${ }^{36}$.

En la misma línea se ha sostenido que:

No obstante, a diferencia de lo recién descrito, la protección relativa a la garantía del artículo 19 $\mathrm{N}^{\circ} 8$ sobre el derecho a vivir en un medio ambiente libre de contaminación, tiene reglas diferentes ya que sólo procede en contra de actos u omisiones ilegales, sin que sea posible esgrimirlo frente a actos arbitrarios (inciso segundo del art. 20 de la CPR). (...) Lo anterior es relevante, debido a que muchas materias relacionadas al medioambiente se encuentran reguladas a través de normativas generales que dejan un amplio margen a la discrecionalidad de la autoridad competente, por lo que la mayor parte de los conflictos ambientales surgen de la existencia de "arbitrariedades", ya sea emanadas de las autoridades o de los particulares, las cuales no pueden ser impugnados mediante la acción de protección ${ }^{37}$.

Por su parte, el artículo 20 inciso segundo exige además en materia ambiental que el acto u omisión sea "imputable a una autoridad o persona determinada". En relación a este punto se ha mencionado que

En cuanto a la legitimación pasiva este derecho es exigible a una autoridad o persona determinada, no debe escapar que resulta muy difícil la relación de causalidad entre la conducta que genera el hecho contaminante y la contaminación en sí, y muy dificultoso de determinar justamente al sujeto contaminante ${ }^{38}$.

Sobre este tema la jurisprudencia ha tenido una interpretación más flexible del texto al disponer en una de sus sentencias que:

En efecto, si bien el artículo 20 inciso segundo de la Constitución Política de la República puntualiza que en el caso del № 8 del artículo 19 procederá la acción cuando el derecho a vivir en un medio ambiente libre de contaminación sea afectado por un acto u omisión ilegal imputable a una autoridad o persona determinada, lo cierto es que en la especie ese requisito se cumple a

\footnotetext{
${ }^{35}$ Historia de la Ley $\mathrm{N}^{\circ} 20.050$, p. 161. Disponible en https://bit.ly/3cKpgqp

36 Vargas (2007), p. 437.

${ }^{37}$ FIMA (2018), p. 17.

${ }^{38}$ Lucas (2007), p. 245.
} 
cabalidad, pues la acción se ha dirigido en contra de cuatro empresas que se individualizan y además se ha solicitado informe al Seremi de Salud de la Región del Maule y a la Superintendencia de Servicios Sanitarios. (...) Por otra parte no es factible rechazar el arbitrio porque la actora afirme que desconoce el origen de la contaminación, puesto que no puede exigirse a un particular que señale con certeza cuáles son las sustancias que producen la contaminación, pues es la autoridad sanitaria quien debe determinar qué tipo de elementos son los que la provocan, ello sin perjuicio de consignar que en el caso de autos la actora ha señalado concretamente que la contaminación se produce porque se vierten al cauce del Estero Carretón residuos industriales líquidos (RIL), por parte de empresas agroindustriales del sector ${ }^{39}$.

Finalmente, se encuentra la discusión respecto del alcance del término "afectado", señalándose que

Por último, en materia ambiental, a diferencia de los otros derechos, la acción surge cuando el derecho a vivir en un medio ambiente libre de contaminación "sea afectado". Se origina pues la duda de si para el potencial éxito de la acción es indispensable que se produzca un atentado efectivo en su ejercicio legítimo (privándolo o perturbándolo), o si también aplica a su respecto un agravio en grado de amenaza ${ }^{40}$.

Con relación a este punto, parte de la doctrina ha sido más categórica expresando que "el recurso ambiental sólo procede en los casos de afectación concreta y no en casos de amenaza a la afectación del derecho"41.

Sin perjuicio de lo anterior, esta es una opinión dividida, expresando parte de la doctrina que

El enunciado del inciso primero se refiere a la privación perturbación o amenaza en el legítimo ejercicio de los derechos enumerados en tanto que el inciso 2 señala que procede también el recurso cuando el derecho a vivir en un medio ambiente libre de contaminación sea "afectado" por un acto u omisión ilegal. La diferencia estará en que la afectación podrá no incluir la amenaza sin embargo a nuestro entender la diferencia de los enunciados es una mera cuestión de estilo ${ }^{42}$.

Por su parte, la jurisprudencia se ha inclinado por esta tesis en diversas ocasiones acogiendo recursos de protección en base a la amenaza del derecho a vivir en un medio ambiente libre de contaminación ${ }^{43}$.

Así las cosas, no obstante, las diversas interpretaciones y discusiones que puedan derivar de la lectura del artículo 20, se puede observar que a pesar de los avances de la reforma del 2005, esta norma otorga la acción de protección con requisitos más restrictivos para el medio ambiente que para los otros derechos, debido a que no procede respecto de actos arbitrarios, se

\footnotetext{
${ }^{39}$ Corte Suprema, Rol N 1960-2012, de 27 de agosto de 2012.

Corte Suprema, Rol N ${ }^{\circ}$ 7041-2012, de 25 de noviembre de 2012.

40 FIMA (2018), p. 18.

${ }^{41}$ Galdámez (2016), p. 131.

42 Durán (2005), p.274.

${ }^{43}$ Corte Suprema, Rol N 7844-2013, de 25 de noviembre de 2013.
} 
debe interponer respecto de persona determinada y no es claro si es que procede ante amenazas o no.

\subsection{LA TUTELA DE LA PRESERVACIÓN DE LA NATURALEZA}

En cuanto a este punto la doctrina ha afirmado que:

Es claro y categórico que la obligación establecida por el constituyente no distingue respecto de qué tipo de "naturaleza" le corresponde proteger al Estado ni qué se entiende por "naturaleza". Aplicando el concepto negativo de naturaleza, como que es todo aquello que no es creado por el hombre, podríamos señalar que la tutela de la preservación de la naturaleza impone a los poderes del Estado la obligación de proteger y preservar el entorno natural ${ }^{44}$.

En esta línea se ha sostenido por la doctrina que este concepto de naturaleza no contempla los elementos de carácter artificial que si componen el concepto de medio ambiente, establecido en el literal ll) del artículo 2o de la LBGMA. Así, Bermúdez ha mencionado que

la preservación de la naturaleza constituye un concepto estrictamente ambiental que tiene como objeto la acción de mantener los elementos ambientales de carácter natural. En efecto, la acción de mantener las condiciones, no dice relación con todos los elementos ambientales, sino sólo con las especies y ecosistemas del país ${ }^{45}$.

De esta manera, además de ser difusa la obligación, no constituye una tutela respecto de todos los elementos del medio ambiente, dejando el deber activo de protección del medio ambiente incompleto.

Otro tema que es necesario relevar a la hora de analizar el deber de preservación de la naturaleza, dice relación con el resguardo de este bien jurídico para el disfrute satisfactorio de generaciones presentes y futuras. En este sentido, cabe señalar que es la administración pública quien tiene la potestad para autorizar y fiscalizar el desarrollo de proyectos y actividades de inversión que potencialmente pueden menoscabar el medio ambiente, situación que ha sido abordada en variados fallos que hacen reconocimiento al principio de desarrollo sustentable. La Corte de Apelaciones de Valparaíso, en el contexto de la situación ambiental asociada al cordón industrial de Concón, Quintero y Puchuncaví, hace referencia a este principio señalando que

el desarrollo económico, como aquel representado por la creación del Complejo Industrial Ventanas, aun cuando legítimamente pretende una mejora en la calidad de vida de las personas, incluyendo a las que viven en Quintero, Ventanas y Puchuncaví, no se puede realizar olvidando ni

\footnotetext{
${ }^{44}$ Bórquez (1993), p. 14.

${ }^{45}$ Bermúdez (2014), p.78.
} 
dejando de lado la conservación y protección del medio ambiente, a la vez que tampoco puede comprometer las expectativas de las generaciones futuras ${ }^{46}$.

Por su parte, la Corte Suprema ha indicado respecto al actuar del sector público y privado que

el sector público, tanto como ente fiscalizador y regulador de las actividades productivas; $y$, en muchas ocasiones como contaminante esto es, en el papel de un particular más. Ello implica que todos los sectores del país deben desarrollar las actividades que les son propias dentro de un esquema de respeto por el medio ambiente, y que la explotación de los recursos naturales debe ser realizada de tal modo que se asegure su sustentabilidad en el futuro ${ }^{47}$.

Así, es posible considerar que para tutelar la preservación de la naturaleza, cobra relevancia el modelo de desarrollo sustentable que debiese inspirar el actuar de los entes privados y públicos en su rol de regulador, fiscalizador y desarrollador de actividades.

\section{Aspectos metodológicos del análisis de otras constituciones}

Con el objetivo de caracterizar el contenido de las normas en materia ambiental en la experiencia comparada e identificar aspectos que podrían ser incorporados en una nueva constitución política para Chile, se analizan las constituciones de 4 países con características relevantes y similitudes a la realidad de nuestro país. Al respecto, se eligieron las constituciones de Costa Rica, Ecuador, Colombia y España.

Los casos de Costa Rica, Ecuador y Colombia fueron escogidos por ser países latinoamericanos con una realidad sociocultural similar a la de Chile y con una historia común como colonias españolas, a su vez se consideraron estas constituciones por haber sido producto de un proceso de asamblea constituyente. El caso de Costa Rica se eligió además por el destacado desempeño en materia medioambiental que tiene el país en comparación con otros países de la región. Por otro lado, se optó por España debido a la influencia que las normas de este país han tenido en la legislación chilena, así como por la similitud climática entre ambos.

A través de un análisis de las constituciones en cuestión, la revisión de doctrina y de jurisprudencia de los respectivos países, y teniendo en consideración las discusiones y deficiencias expuestas en el capítulo anterior, se utilizaron seis criterios de análisis para el estudio, los cuales se describen a continuación:

\footnotetext{
${ }^{46}$ Corte de Apelaciones de Valparaíso, Rol №5888-2019, de 28 de mayo de 2019.

${ }^{47}$ Corte Suprema, Rol №15549-2017, de 8 de enero de 2018.
} 
a. Ubicación de la protección del medio ambiente en la constitución: analiza de forma enunciativa en qué artículos de la constitución se establece la norma principal que consagra la protección del Medio Ambiente. Además, se describe la forma en la cual está redactada este derecho o principio.

b. Carácter individual o colectivo del derecho: examina si el derecho consagrado tiene un carácter individual, o colectivo, en virtud de la posibilidad de interponer la acción que lo protege.

c. Características de la acción destinada a proteger el derecho: caracteriza la acción destinada en la constitución para proteger o garantizar el derecho relacionado con el medio ambiente.

d. Visión antropocéntrica o ecocéntrica del medio ambiente: analiza si es que la constitución considera una protección del medio ambiente en cuanto a la relación que éste tiene con el ser humano, o si es que se protege al medio ambiente en sí mismo.

e. Inclusión de un modelo de desarrollo sostenible: examina la existencia de una mención expresa a un modelo de desarrollo sostenible o si es que este ha sido desarrollado de manera jurisprudencial.

f. Consagración de otros derechos relacionados con el medio ambiente: destaca la inclusión de temáticas emergentes o que puedan resultar útiles para una protección más robusta del medioambiente en las constituciones analizadas, como la adaptación y mitigación del cambio climático, la figura de un defensor del pueblo, entre otros.

\section{La protección del medio ambiente en otras constituciones}

\subsection{COLOMBIA}

La Constitución de Colombia data del 4 de julio de 1991 y fue creada vía Asamblea Constituyente. La protección del medio ambiente no formaba parte del texto constitucional anterior (Constitución de 1886), debiéndose su inclusión al compromiso de reconocimiento y protección al derecho de gozar de un medio ambiente sano, asumido por este país en la Conferencia de Estocolmo ${ }^{48}$.

${ }^{48}$ Melón (2016), p. 212. 
La introducción del aspecto medio ambiental en la constitución fue de tal envergadura que la jurisprudencia colombiana la ha denominado como la "constitución ecológica". Al respecto, mediante sentencia C-126 del 1 de abril de 1998, la Corte Constitucional Colombiana estableció "que la protección del medio ambiente ocupa un lugar tan trascendental en el ordenamiento jurídico que la Carta contiene una verdadera "constitución ecológica", conformada por todas aquellas disposiciones que regulan la relación de la sociedad con la naturaleza y que buscan proteger el medio ambiente". Además expresó que "la protección al medio ambiente es un principio que irradia todo el orden jurídico puesto que es obligación del Estado proteger las riquezas naturales de la Nación"49.

\subsubsection{Ubicación de la protección del Medio Ambiente en la constitución}

Sin perjuicio que a lo largo de la constitución es posible encontrar alrededor de 40 artículos con contenido ambiental, su principal disposición corresponde al artículo № 79, del capítulo III "De los derechos colectivos y del ambiente" que establece

todas las personas tienen derecho a gozar de un ambiente sano. La ley garantizará la participación de la comunidad en las decisiones que puedan afectarlo. Es deber del Estado proteger la diversidad e integridad del ambiente, conservar las áreas de especial importancia ecológica y fomentar la educación para el logro de estos fines.

Del análisis del articulado con contenido ambiental, se puede deprender que la protección del medio ambiente se aborda desde tres perspectivas: como principio fundamental del ordenamiento jurídico, como derecho de todas las personas a gozar de un medio ambiente sano, y como un mandato que contiene obligaciones para las autoridades y particulares.

\subsubsection{Carácter individual o colectivo del derecho}

El artículo 88 de la Constitución de Colombia consagra al medio ambiente como un derecho colectivo. Dicha disposición estipula que

La ley regulará las acciones populares para la protección de los derechos e intereses colectivos, relacionados con el patrimonio, el espacio, la seguridad y la salubridad públicas, la moral administrativa, el ambiente, la libre competencia económica y otros de similar naturaleza que se definen en ella.

Esta norma ha sido interpretada por la jurisprudencia de forma amplia, al afirmar que:

${ }^{49}$ Corte Constitucional Colombiana, Rol $\mathrm{N}^{\circ} \mathrm{C}-126-1998$, de 1 de abril de 1998. Lo anterior ha sido ratificado por diversas sentencias, tales como: C-449-15, T-325-17, C-032-19. 
La conservación del medio ambiente no solo es considerada como un asunto de interés general, sino principalmente como un derecho de rango constitucional del cual son titulares todos los seres humanos, en conexidad con el ineludible deber del Estado de garantizar la vida de las personas en condiciones dignas, precaviendo cualquier injerencia nociva que atente contra su salud. Para el efecto, la Constitución de 1991 impuso al Estado la obligación de asegurar las condiciones que permitan a las personas gozar del derecho a un medio ambiente sano, y dispuso el deber de todos de contribuir a tal fin mediante la participación en la toma de decisiones ambientales (art. $95.8 \mathrm{CP}$ ) y el ejercicio de acciones públicas (Art. $88 \mathrm{CP}$ ) y otras garantías individuales, entre otros ${ }^{50}$.

\subsubsection{Mecanismos que garanticen el derecho a un medio ambiente sano}

Como se mencionó anteriormente el medio ambiente sano, se ha catalogado como un derecho colectivo, teniendo como mecanismos de protección la acción popular y de grupo. Así, la doctrina ha indicado que "la amenaza o vulneración al derecho a un Medio Ambiente sano, es decir, al conjunto de condiciones naturales que permiten la supervivencia y la existencia digna en el medio que nos rodea, tiene como mecanismo de protección acciones constitucionales como la acción popular y la acción de grupo" 51 .

En este sentido, el artículo 88 delega en una ley la regulación de una acción popular y de grupo para la protección de derechos e intereses colectivos, donde se encuentra "el ambiente". Dicho mandato corresponde a la Ley № 472 del 5 de agosto de 1998 que en su artículo 9o establece que "las acciones populares proceden contra toda acción u omisión de las autoridades públicas o de los particulares, que hayan violado o amenacen violar los derechos e intereses colectivos". Respecto a los titulares de la acción, se menciona que podrán ejercer estas acciones toda persona natural o jurídica, Organizaciones No Gubernamentales, Populares o Cívicas, Entidades Públicas y los alcaldes. En lo que refiere a los destinatarios de la acción, el artículo 14 dispone que se "dirigirá contra el particular, persona natural o jurídica, o la autoridad pública cuya actuación se considere amenazada, viola o ha violado el derecho o interés colectivo. En caso de existir la vulneración o amenaza y se desconozcan los responsables, corresponderá al juez determinarlos".

Sin perjuicio de lo anterior, la jurisprudencia colombiana ha señalado además, que el derecho al medio ambiente sano, corresponde a un derecho humano. Al respecto,

No obstante que la acción de tutela ha sido consagrada para proteger los derechos constitucionales fundamentales de carácter individual, es procedente intentar ésta, cuando se trata de la presunta vulneración o amenaza de un derecho relativo al ambiente sano, pues en estos casos, en presencia de la conexidad de los derechos colectivos y fundamentales vulnerados,

\footnotetext{
${ }^{50}$ Corte Constitucional Colombiana, Rol No T-341-16, de 24 de agosto de 2018.

${ }^{51}$ Mesa (2001), p.93.
} 
prevalece la acción de tutela sobre las acciones populares, convirtiéndose así en el instrumento judicial adecuado para el amparo oportuno de los derechos amenazados" 52 . En esta línea, se ha sentenciado que "si de la vulneración del derecho a un medio ambiente sano (art. 79 C.N.) se sigue la vulneración de un derecho constitucional fundamental, como la salud, la vida, la tranquilidad o la intimidad, procede la acción de tutela como mecanismo ${ }^{53}$.

La referida jurisprudencia, permite por tanto, que se aplique a estas materias la acción de tutela propia de los derechos fundamentales. En este sentido, el artículo 86 de la Constitución prescribe que

toda persona tendrá acción de tutela para reclamar ante los jueces, en todo momento y lugar, mediante un procedimiento preferente y sumario, por sí misma o por quien actúe a su nombre, la protección inmediata a sus derechos constitucionales fundamentales, cuando quiera que éstos resulten vulnerados o amenazados por la acción o la omisión de cualquier autoridad pública.

En suma, el derecho a un medio ambiente sano, por ser entendido como un derecho colectivo puede ser protegido mediante la acción popular y de grupo, y además mediante la acción de tutela, debido a que la jurisprudencia lo está abordando como un derecho humano.

\subsubsection{Carácter antropocéntrico o ecocéntrico del derecho}

La protección del medio ambiente establecida en el articulado de la Constitución de Colombia tiene un enfoque antropocéntrico. No obstante, en los últimos años se observa en la jurisprudencia un cambio hacia un enfoque ecocéntrico.

En esta línea, la Corte Constitucional ha afirmado que

en la actualidad, la naturaleza no se concibe únicamente como el ambiente y entorno de los seres humanos, sino también como un sujeto con derechos propios, que, como tal, deben ser protegidos y garantizados. En este sentido, la compensación ecosistémica comporta un tipo de restitución aplicada exclusivamente a la naturaleza ${ }^{54}$.

Además, ha indicado que

la jurisprudencia constitucional ha atendido los saberes ancestrales y las corrientes alternas de pensamiento, llegando a sostener que la naturaleza no se concibe únicamente como el ambiente y entorno de los seres humanos, sino también como un sujeto con derechos propios, que, como tal, deben ser protegidos y garantizados ${ }^{55}$.

Otro ejemplo en este mismo sentido señala que:

El desafío más grande que tiene el constitucionalismo contemporáneo en materia ambiental, consiste en lograr la salvaguarda y protección efectiva de la naturaleza, las culturas y formas de

\footnotetext{
${ }^{52}$ Corte Constitucional Colombiana, Rol № SU-442-97, de 16 de septiembre de 1997.

${ }^{53}$ Corte Constitucional Colombiana, Rol № T-975-00, de 31 de julio de 2000.

${ }^{54}$ Corte Constitucional Colombiana, Rol № C-632-2011, de 24 de agosto de 2011.

${ }^{55}$ Corte Constitucional Colombiana, Rol № T-080-2015, de 20 de febrero de 2015.
} 
vida asociadas a ella y la biodiversidad, no por la simple utilidad material, genética o productiva que estos puedan representar para el ser humano, sino porque al tratarse de una entidad viviente compuesta por otras múltiples formas de vida y representaciones culturales, son sujetos de derechos individualizables, lo que los convierte en un nuevo imperativo de protección integral y respeto por parte de los Estados y las sociedades ${ }^{56}$.

Por lo tanto, sin perjuicio que el texto constitucional se refiera al derecho a un medio ambiente sano desde un enfoque antropocéntrico, es posible observar un cambio jurisprudencial en la interpretación de dichas disposiciones, en la que se empieza a reconocer a la naturaleza como un sujeto de derecho autónomo.

\subsubsection{Inclusión de modelo de desarrollo sostenible}

El artículo 80 de la Constitución, prescribe que "el Estado planificará el manejo y aprovechamiento de los recursos naturales, para garantizar su desarrollo sostenible...".

La jurisprudencia ha definido al desarrollo sostenible como

el modelo de desarrollo que permite satisfacer las necesidades de las generaciones presentes sin comprometer la capacidad de las generaciones futuras para satisfacer las suyas propias. Esto implica que, para la satisfacción de las necesidades actuales, debe efectuarse un ejercicio de planificación económica y de asunción de responsabilidad en materia ambiental en el modelo de desarrollo. Especial énfasis se ha puesto en garantizar las necesidades esenciales de los sectores menos favorecidos de la población; acento que, conforme lo ha establecido esta Corporación, se hace más importante en países como los nuestros, donde la pobreza mayoritaria está unida a la escasez, pues no habrá desarrollo sostenible mientras casi la mitad de la población viva niveles de extrema pobreza ${ }^{57}$.

Además, se ha establecido que el principio de desarrollo sostenible se ha construido sobre el concepto de solidaridad intergeneracional ${ }^{58}$. En este sentido, la jurisprudencia ha sostenido que la solidaridad intergeneracional "consiste en satisfacer las necesidades de las generaciones presentes, pero sin comprometer la capacidad de las generaciones futuras para satisfacer las propias"59.

\subsubsection{Consagración de otros derechos relacionados con el medio ambiente}

Dentro de los otros derechos que contempla la Constitución de Colombia relacionados con este tema, cabe destacar que al derecho de propiedad se le reconoce una función ecológica en el artículo 58 inciso $2^{\text {o }}$ "la propiedad es una función social que implica obligaciones, como tal, le es inherente una función ecológica". En este orden, además, se dispone que ciertos bienes asociados

\footnotetext{
${ }^{56}$ Corte Constitucional Colombiana, Rol № T-622-2016, de 10 de noviembre de 2016.

${ }^{57}$ Corte Constitucional Colombiana, Rol № C-644-17, de 18 de octubre de 2017.

${ }^{58}$ Londoño, et al (2010), p.23.

${ }^{59}$ Corte Constitucional Colombiana, Rol № C-094-15, de 10 de marzo de 2015.
} 
al medio ambiente son inalienables, imprescriptibles e inembargables, señalándose en el artículo 63 que "los bienes de uso público, las tierras comunales de grupos étnicos, las tierras de resguardo, el patrimonio arqueológico de la Nación y los demás bienes que determine la ley, son inalienables, imprescriptibles e inembargables".

Por su parte, el artículo 277, enumera dentro de las funciones del Procurador General de la Nación "defender los intereses colectivos, en especial el ambiente". Éste corresponde a un órgano autónomo que investiga, sanciona, interviene y previene las irregularidades cometidas por gobernantes, funcionarios públicos, particulares que ejercen funciones públicas y agencias del Estado. A su vez, el artículo 282, se refiere a la figura del Defensor del Pueblo, el cual tiene como objeto principal "velar por la promoción, el ejercicio y la divulgación de los derechos humanos". Junto con lo anterior, se enumeran sus funciones dentro de las cuales destaca la de “interponer acciones populares en asuntos relacionados con su competencia”. Al respecto, los artículos 72 y siguientes de la Ley № 99 General Ambiental de Colombia, establecen que dentro de estas competencias se encuentra la defensa de los derechos colectivos (dentro de los cuales se encuentra el medio ambiente sano).

\subsection{COSTA RICA}

\subsubsection{Ubicación de la protección del medio ambiente en la constitución}

La Constitución de Costa Rica que data del 7 de noviembre de 1949 y fue creada vía Asamblea Constituyente, contiene diversas menciones al medio ambiente y los recursos naturales que a través de interpretaciones jurisprudenciales han logrado generar una vasta protección del medio natural.

La consagración más importante de este derecho se incorporó en el año 199460, mediante el artículo 50, que se encuentra en el título V como un derecho y garantía social. Este artículo establece:

El Estado procurará el mayor bienestar a todos los habitantes del país, organizando y estimulando la producción y el más adecuado reparto de la riqueza. (...) Toda persona tiene derecho a un ambiente sano y ecológicamente equilibrado. Por ello, está legitimada para denunciar los actos que infrinjan ese derecho y para reclamar la reparación del daño causado. (...) El Estado garantizará, defenderá y preservará ese derecho. La ley determinará las responsabilidades y las sanciones correspondientes.

${ }^{60}$ Ley N7.412, Reforma Constitucional (art. 50), de 24 de mayo de 1994. 


\subsubsection{Carácter individual o colectivo del derecho}

La constitución costarricense consagra el derecho a un medio ambiente sano como un derecho colectivo, ya que corresponde a cualquier persona el ejercicio de esta acción y no sólo a los directamente afectados.

En esta línea la doctrina de este país ha expresado que

Se trata de un derecho no sólo individual sino, además, colectivo en razón de lo cual la legitimación para procurar su tutela judicial corresponde a cualquier persona y no sólo a quién vea afectado su esfera privada de intereses. Es un derecho que tutela un interés colectivo cuyo sujeto titular es, por lo mismo, la colectividad entendida como el conjunto de los habitantes del país, no sólo los nacionales ni sólo los ciudadanos ${ }^{61}$.

A su vez, se ha sostenido que

El ordinal 50 constitucional confiere a toda persona un verdadero derecho subjetivo, pero de alcance general, es decir, incumbe a la totalidad de personas, lo que ha llegado a evolucionar en grados de legitimación de tal amplitud que permiten la interposición de acciones vinculadas solo a cuestiones objetivas, para la defensa y restitución del ambiente ${ }^{62}$.

\subsubsection{Mecanismos que garantice el derecho a un medio ambiente sano}

La constitución costarricense no contempla un recurso de protección, sin embargo, establece un recurso de amparo. En este sentido, el artículo 48 dispone

Toda persona tiene derecho al recurso de hábeas corpus para garantizar su libertad e integridad personales, y al recurso de amparo para mantener o restablecer el goce de los otros derechos consagrados en esta Constitución, así como de los de carácter fundamental establecidos en los instrumentos internacionales sobre derechos humanos, aplicables a la República.

Por su parte, la Ley № 7.135 de la Jurisdicción Constitucional en su título III regula este recurso más a fondo, señalando en su artículo 29 que

[...]Procede el recurso contra toda disposición, acuerdo o resolución y, en general, contra toda acción, omisión o simple actuación material no fundada en un acto administrativo eficaz, de los servidores y órganos públicos, que haya violado, viole o amenace violar cualquiera de aquellos derechos. (...). El amparo procederá no sólo contra los actos arbitrarios, sino también contra las actuaciones $\mathrm{u}$ omisiones fundadas en normas erróneamente interpretadas o indebidamente aplicadas.

En el artículo 57 se establece el amparo en contra de personas de derecho privado,

cuando éstos actúen o deban actuar en ejercicio de funciones o potestades públicas, o se encuentren, de derecho o de hecho, en una posición de poder frente a la cual los remedios

\footnotetext{
${ }^{61}$ Jurado (2016), p. 41.

${ }^{62}$ Garita y Jiménez (2016), p.170.
} 
jurisdiccionales comunes resulten claramente insuficientes o tardíos para garantizar los derechos o libertades fundamentales a que se refiere el artículo 2, inciso a), de esta ley.

De esta manera, se puede observar que el recurso de amparo tiene una vasta aplicación, ya que además de poder interponerse respecto de todas las garantías constitucionales por igual, dentro de las que se encuentra el derecho establecido en el artículo 50 de la constitución, procede respecto amenaza y violación, y en contra de actos arbitrarios, erróneamente interpretados o indebidamente aplicados. Sin embargo, cabe señalar que sólo se puede deducir respecto del Estado, funcionarios públicos o empresas privadas que encuentren realizando una función pública o que se encuentren en una posición de poder.

\subsubsection{Carácter antropocéntrico o ecocéntrico del derecho}

Con anterioridad a la reforma del año 1994, el derecho a un medio ambiente sano fue creado jurisprudencialmente ${ }^{63}$ en base al artículo 21 (vida humana inviolable). Al respecto, se ha mencionado

De esta manera, aún antes de la reforma al artículo 50 en 1994, ya la Sala Constitucional había considerado que dicho derecho podía desprenderse, utilizando criterios de interpretación sistemáticos y evolutivos, de lo dispuesto en otros artículos de la Carta Magna, tales como del artículo 21 (derecho a la salud), considerando que una de las condiciones para gozar de ésta lo constituye la existencia de un ambiente libre de contaminación ${ }^{64}$.

De esta forma, desde la génesis de esta garantía, se relacionó el derecho a un medio ambiente sano con el derecho a una vida humana inviolable y por lo mismo con la afectación de humanos, sin considerar al medio ambiente como un sujeto de derechos por sí solo.

En este orden de ideas, la doctrina de este país ha expresado que:

Es nuestro criterio, que esas palabras (toda persona) son fundamentales para limitar interpretaciones más novedosas y progresistas, pues se parte de que lo ecológico y lo equilibrado del ambiente, van en razón a las necesidades humanas; y a nuestro entender, ello frena incluir, por ejemplo, a sujetos no humanos en específico. Es claro, que algunos jueces de tendencia progresista podrían hacer interpretaciones extensivas para llegar a considerar dar derechos a la biodiversidad cosa que ha ocurrido y es innegable, pero en la forma que está redactada actualmente la norma, es más difícil poder dar el salto a la visión biocéntrica, puesto que todo queda a la buena o mala óptica de los operadores de justicia, tanto judicial, como administrativa ${ }^{65}$.

Así las cosas, esta constitución, a pesar de contemplar una amplia titularidad, no tiene una visión ecocéntrica y deriva la afectación del medio ambiente sano a las personas.

\footnotetext{
${ }^{63}$ La sentencia №3705-1993, es la primera en pronunciarse sobre el medio ambiente sano.

${ }^{64}$ Cabrera (2016), p.67.

${ }^{65}$ Sagot (2016) p. 121.
} 


\subsubsection{Inclusión de modelo de desarrollo sostenible}

A pesar de no existir una inclusión expresa de un modelo de desarrollo sostenible en la constitución, de la redacción del artículo 50 y la relación existente entre sus tres incisos, la jurisprudencia constitucional ha interpretado que el desarrollo económico y social del país debe ser sostenible. En esta línea, la doctrina costarricense ha expresado:

El artículo 50 constitucional establece en su primer párrafo la obligación del Estado de estimular la producción y procurar un adecuado reparto de la riqueza. Esta obligación ha sido asumida como principio constitucional consistente, precisamente, en la obligación estatal de ejecutar políticas de fomento de la producción y de distribución de la riqueza. El segundo y tercer párrafos del artículo 50 son los que establecen el derecho a un ambiente sano y ecológicamente equilibrado como derecho subjetivo y el principio constitucional según el cual el Estado debe tutelar ese derecho, es decir, proteger el ambiente. (...) Los párrafos segundo y tercero condicionan los alcances del primer párrafo. Es decir, el desarrollo económico y social que impulsan las políticas de fomento de la producción y distribución de la riqueza deben compaginarse con la protección del ambiente. En consecuencia, estamos hablando de un desarrollo económico y social que, por mandato constitucional, debe ser sostenible. La jurisprudencia constitucional costarricense ha interpretado el artículo 50 desde esta perspectiva ${ }^{66}$.

En este orden de ideas, la jurisprudencia constitucional ha afirmado que:

Sin embargo, ante la finalidad del interés general de la colectividad nacional se deben ponderar ambos derechos y equilibrar su utilización atendiendo a un principio de desarrollo humano sostenible, según el cual se reconoce la necesidad de una inter-relación equilibrada entre los elementos críticos del desarrollo económico (turismo, inversión, empleo, infraestructura, finanzas sanas y sistema tributario) de la política social (educación, salud, seguridad) y de la protección medioambiental. Este desarrollo ha sido definido por la Organización de las Naciones Unidas, como la ampliación de las opciones para todas las personas de una sociedad, el cual es un concepto compresivo porque incluye a los hombres y mujeres como centro del desarrollo, la protección de las oportunidades en la vida de las futuras generaciones y los sistemas naturales de los que depende la vida en su totalidad ${ }^{67}$.

\subsubsection{Consagración de otros derechos relacionados con el medio ambiente}

Dentro de los otros derechos que contempla la constitución de Costa Rica relacionados con este tema, destaca el derecho de los consumidores al medio ambiente ${ }^{68}$. Además, existen dos artículos relacionados con la obligación del estado de tutelar el medio ambiente, mediante la protección y conservación de los recursos naturales en la zona marítima económica exclusiva69,

\footnotetext{
${ }^{66}$ Jurado (2016), pp. 43-44.

${ }^{67}$ Corte Suprema de Costa Rica. Expediente 08-014068-0007-CO, de 16 de abril de 2010.

${ }^{68}$ Artículo 46.-...Los consumidores y usuarios tienen derecho a la protección de su salud, ambiente, seguridad e intereses económicos; a recibir información adecuada y veraz; a la libertad de elección y a un trato equitativo...

${ }^{69}$ Artículo 6.-... Ejerce además, una jurisdicción especial sobre los mares adyacentes a su territorio en una extensión de doscientas millas a partir de la misma línea, a fin de proteger, conservar y explotar con exclusividad todos los recursos y riquezas naturales existentes en las aguas, el suelo y el subsuelo de esas zonas, de conformidad con aquellos principios.
} 
y la obligación de proteger las bellezas naturales ${ }^{70}$. Asimismo, el artículo $69^{71}$ estipula la explotación racional de la tierra en los contratos de aparcería rural, obligación que ha sido interpretada extensivamente por la Sala Constitucional respecto de todos los recursos naturales y no solo en el caso de los contratos de aparcería rural72.

\subsection{ECUADOR}

\subsubsection{Ubicación de la protección del medio ambiente en la constitución}

La Constitución Ecuatoriana del año 2008, creada mediante Asamblea Constituyente, contiene alrededor de 40 artículos relacionados con la temática ambiental, los cuales se encuentran en distintos capítulos de ésta, constituyendo la protección del medio ambiente un principio, un derecho relacionado con las personas, un derecho por sí mismo, un elemento del modelo de desarrollo, una obligación del Estado y de los ciudadanos, entre otros.

En cuanto a los derechos, el artículo $66 \mathrm{~N}^{\circ} 27$ reconoce y garantiza a las personas “EI derecho a vivir en un ambiente sano, ecológicamente equilibrado, libre de contaminación y en armonía con la naturaleza"73. Sin embargo, la mayor innovación en esta materia se encuentra en el artículo 10 que establece en su inciso segundo "La naturaleza será sujeto de aquellos derechos que le reconozca la Constitución”. En complemento los artículos 71 y 72 regulan este derecho al disponer "La naturaleza o Pacha Mama, donde se reproduce y realiza la vida, tiene derecho a que se respete integralmente su existencia y el mantenimiento y regeneración de sus ciclos vitales, estructura, funciones y procesos evolutivos".

\subsubsection{Carácter individual o colectivo del derecho}

La Constitución Ecuatoriana en su artículo 11 estipula que "EI ejercicio de los derechos se regirá por los siguientes principios: (...) 1. Los derechos se podrán ejercer, promover y exigir de forma individual o colectiva ante las autoridades competentes; estas autoridades garantizarán su cumplimiento". Complementando esta norma, el artículo 86 establece que "Las garantías jurisdiccionales se regirán, en general, por las siguientes disposiciones: (...) 1. Cualquier persona, grupo de personas, comunidad, pueblo o nacionalidad podrá proponer las acciones previstas en

\footnotetext{
${ }^{70}$ Artículo 89.- Entre los fines culturales de la República están: proteger las bellezas naturales, conservar y desarrollar el patrimonio histórico y artístico de la Nación....

${ }^{71}$ Artículo 69.- Los contratos de aparcería rural serán regulados con el fin de asegurar la explotación racional de la tierra y la distribución equitativa de sus productos entre propietarios y aparceros.

${ }^{72}$ Corte Suprema de Costa Rica. Expediente: 00-007814-0007-CO, de 03 de julio de 2003.

${ }^{73}$ Este derecho a su vez se relaciona con los artículos 396 y siguientes que regulan el daño ambiental.
} 
la Constitución”. Por su parte, el artículo 38 Código Orgánico General de Procesos de Ecuador, prescribe que "La naturaleza podrá ser representada por cualquier persona natural o jurídica, colectividad o por el Defensor del Pueblo, quien además podrá actuar por iniciativa propia".

Por su parte, la jurisprudencia constitucional ha interpretado esta normativa de forma extensiva, señalando

En el caso, para el ejercicio de las acciones correspondientes en el campo ambiental se ha otorgado legitimación activa o aptitud para ser parte en un proceso concreto a los ciudadanos, grupos determinados y organizaciones; ello les permite presentar acciones, sin necesidad de mostrar un interés personal y directo en el daño ambiental producido contra el ilícito contra el cual reclaman ${ }^{74}$.

Asimismo, la doctrina ha agregado que

En conclusión, las acciones jurisdiccionales pueden ser interpuestas por cualquier persona, grupo de personas, pueblo o nacionalidad, aun cuando no sean directamente afectadas y por otra parte, al ser todos los derechos plenamente justiciables, las acciones jurisdiccionales pueden interponerse por cualquier derecho, incluyendo los derechos de la Naturaleza ${ }^{75}$.

En este sentido, se puede observar que la constitución ecuatoriana consagra la protección del medio ambiente como un derecho colectivo, ya que existe una legitimación activa bastante amplia para la interposición de las acciones que contempla la constitución para proteger los derechos de las personas relacionados con el medio ambiente y aquellos pertenecientes a la naturaleza por sí misma.

\subsubsection{Mecanismos que garanticen el derecho a un medio ambiente sano}

La Constitución de Ecuador contempla una serie de recursos, acciones o garantías jurisdiccionales para ejercer la protección de los derechos establecidos en ella. Así, se ha señalado que:

La Constitución ecuatoriana, presenta una serie de garantías jurisdiccionales, las cuales tienen por objeto la protección eficaz e inmediata de los derechos reconocidos en la Constitución y en instrumentos internacionales de derechos humanos; la declaración de la violación de uno o varios derechos, así como la reparación integral de los daños causados por su vulneración. (...) Entre ellas, se destacan: la Acción de Protección, la Acción Extraordinaria de Protección, Acceso a la Información, Habeas Data, Medidas Cautelares y la Acción de Incumplimiento. No obstante para efectos de la presente exposición, nos enfocaremos en las dos primeras de ellas ${ }^{76}$.

\footnotetext{
${ }^{74}$ Tribunal Constitucional de Ecuador. Caso N 1236-06-RA, de 19 de septiembre de 2007.

${ }^{75}$ Ayora (2014), p. 40.

${ }^{76}$ Bustamante (2016).
} 
La acción de protección, en específico, se encuentra consagrada en el artículo 88 del texto constitucional, el cual estipula que:

La acción de protección tendrá por objeto el amparo directo y eficaz de los derechos reconocidos en la Constitución, y podrá interponerse cuando exista una vulneración de derechos constitucionales, por actos u omisiones de cualquier autoridad pública no judicial; contra políticas públicas cuando supongan la privación del goce o ejercicio de los derechos constitucionales; y cuando la violación proceda de una persona particular, si la violación del derecho provoca daño grave, si presta servicios públicos impropios, si actúa por delegación o concesión, o si la persona afectada se encuentra en estado de subordinación, indefensión o discriminación ${ }^{77}$.

Además, se establece la procedencia de medidas cautelares, respecto de las cuales se ha mencionado

De igual forma, otra de las garantías jurisdiccionales que sirven para proteger estos derechos son las medidas cautelares. Éstas tienen por objeto evitar o hacer cesar la violación o amenaza de violación de un derecho reconocido en la Constitución y en los instrumentos internacionales sobre derechos humanos; estás pueden ser ordenadas conjunta o independientemente de las acciones constitucionales ${ }^{78}$.

\subsubsection{Carácter antropocéntrico o ecocéntrico del derecho}

Como fue mencionado con anterioridad, además de existir un derecho a un medio ambiente sano, relacionado con los humanos, en los artículos 71 y siguientes de la Constitución de Ecuador se consagra que la naturaleza tiene sus propios derechos. Al respecto, la doctrina ha expresado que "tomando en cuenta estos antecedentes, el caso ecuatoriano tiene un componente diferente al europeo, donde los derechos no son sólo para los individuos sino también para el medio ambiente, son derechos de la naturaleza"79. En este sentido, se ha concluido que

En definitiva, la Constitución ecuatoriana determina que la naturaleza será sujeto de aquellos derechos que le reconozca la Constitución, de lo cual se desprende que por un lado se entregó derechos subjetivos a la naturaleza, reconociendo el valor intrínseco de la naturaleza independientemente de su utilidad y por otro lado, se estableció una reserva constitucional para el establecimiento de estos derechos ${ }^{80}$.

De esta manera, al reconocer la naturaleza como sujeto de derecho subjetivo, en conjunto con el asegurar a las personas un derecho a un medio ambiente sano, la Constitución Ecuatoriana tiene un enfoque ecocéntrico, por sobre uno antropocéntrico.

\footnotetext{
${ }^{77}$ Art. 88 Constitución de la República del Ecuador

${ }^{78}$ Bedón (2017), p. 23.

${ }^{79}$ Velázques- Gutiérrez (2014), p. 233.

${ }^{80}$ Bedón (2017), p. 16.
} 


\subsubsection{Inclusión de modelo de desarrollo sostenible}

La Constitución Ecuatoriana en diversos artículos ${ }^{81}$ establece de forma expresa que el modelo de desarrollo del país es sustentable. En esta línea el artículo 3 dispone: "son deberes primordiales del Estado: (...) 5. Planificar el desarrollo nacional, erradicar la pobreza, promover el desarrollo sustentable y la redistribución equitativa de los recursos y la riqueza, para acceder al buen vivir".

A su vez, el artículo 275 expresa que

El régimen de desarrollo es el conjunto organizado, sostenible y dinámico de los sistemas económicos, políticos, socio-culturales y ambientales, que garantizan la realización del buen vivir, del sumakkawsay. (...) El buen vivir requerirá que las personas, comunidades, pueblos y nacionalidades gocen efectivamente de sus derechos, y ejerzan responsabilidades en el marco de la interculturalidad, del respeto a sus diversidades, y de la convivencia armónica con la naturaleza.

Por su parte, el artículo 276, prescribe dentro de los objetivos del desarrollo "4. Recuperar y conservar la naturaleza y mantener un ambiente sano y sustentable que garantice a las personas y colectividades el acceso equitativo, permanente y de calidad al agua, aire y suelo, y a los beneficios de los recursos del subsuelo y del patrimonio natural".

Finalmente, la jurisprudencia ha analizado al respecto que

Como podemos observar, dentro de este postulado constitucional se determina que el Estado ecuatoriano debe llevar a cabo un desarrollo sustentable en donde se proteja el medio ambiente y la biodiversidad, lo cual permitirá el desarrollo de las generaciones actuales, empero sin comprometer los derechos de las futuras generaciones ${ }^{82}$.

\subsubsection{Consagración de otros derechos relacionados con el medio ambiente}

Además del derecho de la naturaleza por sí misma, el derecho a un medio ambiente sano y las distintas menciones que hemos analizado, la Constitución Ecuatoriana establece la creación de

\footnotetext{
${ }^{81}$ Art. 277.- Para la consecución del buen vivir, serán deberes generales del Estado: (...) 1. Garantizar los derechos de las personas, las colectividades y la naturaleza.

Art. 283.- El sistema económico es social y solidario; reconoce al ser humano como sujeto y fin; propende a una relación dinámica y equilibrada entre sociedad, Estado y mercado, en armonía con la naturaleza; y tiene por objetivo garantizar la producción y reproducción de las condiciones materiales e inmateriales que posibiliten el buen vivir.

Art. 290.- El endeudamiento público se sujetará a las siguientes regulaciones: (...) 2. Se velará para que el endeudamiento público no afecte a la soberanía, los derechos, el buen vivir y la preservación de la naturaleza.

Art. 306.- El Estado promoverá las exportaciones ambientalmente responsables...

También Véase artículos 83, 259, 315, 317, 319, 395, 406, 407, 408, 423, entre otros.

82 Corte Constitucional para el Período de Transición de Ecuador. Caso Nº012-09-IN de 15 de julio de 2010.
} 
un Defensor del Pueblo que garantiza los derechos consagrados en la Constitución, y además dispone el derecho a mitigación y adaptación al cambio climático.

En esta línea, el artículo 214 señala que:

El Defensor del Pueblo será un órgano de derecho público con jurisdicción nacional, personalidad jurídica y autonomía administrativa y financiera. Su estructura será desconcentrada y tendrá delegados en cada provincia y en el exterior". Éste "tendrá como funciones la protección y tutela de los derechos de los habitantes del Ecuador y la defensa de los derechos de las ecuatorianas y ecuatorianos que estén fuera del país. Serán sus atribuciones, además de las establecidas en la ley, las siguientes: (...) 1. El patrocinio, de oficio o a petición de parte, de las acciones de protección, hábeas corpus, acceso a la información pública, hábeas data, incumplimiento, acción ciudadana y los reclamos por mala calidad o indebida prestación de los servicios públicos o privados ${ }^{83}$.

Por su parte, el artículo 414 prescribe que

El Estado adoptará medidas adecuadas y transversales para la mitigación del cambio climático, mediante la limitación de las emisiones de gases de efecto invernadero, de la deforestación y de la contaminación atmosférica; tomará medidas para la conservación de los bosques y la vegetación, y protegerá a la población en riesgo.

\subsection{ESPAÑA}

La Constitución de España data del 29 de diciembre de 1978 y es consecuencia de una reforma realizada por la "Comisión de Asuntos Constitucionales y Libertades Públicas" del Congreso de los Diputados, en el marco del proceso de la transición española hacia la democracia representativa, posterior a la muerte de Francisco Franco ${ }^{84}$.

\subsubsection{Ubicación de la protección del medio ambiente en la constitución}

Esta Carta Magna menciona la protección del medio ambiente en el capítulo III, referido a los "Principios rectores de la política social y económica", no reconociéndolo como un derecho fundamental. Dicha disposición establece que:

1. Todos tienen el derecho a disfrutar de un medio ambiente adecuado para el desarrollo de la persona, así como el deber de conservarlo. 2. Los poderes públicos velarán por la utilización racional de todos los recursos naturales, con el fin de proteger y mejorar la calidad de la vida y defender y restaurar el medio ambiente, apoyándose en la indispensable solidaridad colectiva. 3 . Para quienes violen lo dispuesto en el apartado anterior, en los términos que la ley fije se establecerán sanciones penales o, en su caso, administrativas, así como la obligación de reparar el daño causado.

\footnotetext{
${ }^{83}$ Artículo 215 Constitución de Ecuador.

${ }^{84}$ Varela (2003), p. 42-48.
} 
En relación a la redacción del artículo 45, se ha sostenido que es posible interpretar dos conceptos de medio ambiente

en el apartado número 1 se ofrece un concepto amplio de medio ambiente con una genérica referencia al deber de conservación que a todos nos atañe, mientras que en el apartado número 2 se contiene la expresa obligación de los poderes públicos de velar por la "utilización racional de todos los recursos naturales", en base a una concepción restrictiva de medio ambiente, conectable con sus elementos naturales ${ }^{85}$.

Además, la doctrina española ha señalado que la protección constitucional del medio ambiente se realiza en tres dimensiones "como derecho subjetivo, como deber ciudadano de conservarlo y como principio rector de las actividades del Estado" 86 .

\subsubsection{Carácter individual o colectivo del derecho}

Como se expresó en el apartado anterior, la Constitución española, incluye la protección del medio ambiente como un principio rector de la política social y económica (capítulo III), pero no como un derecho y libertad (capítulo II). No obstante aquello, la doctrina ha afirmado en relación al artículo 45 que

el disfrute no económico de los recursos naturales aparece en el último constitucionalismo social como un derecho, el disfrutar de un medio ambiente adecuado para el desarrollo de la persona. Este disfrute estético, espiritual, era antes sólo protagonizado por una minoría, ahora su constitucionalización implica su generalización como bien colectivo ${ }^{87}$.

En la misma línea, se ha señalado que

se trata de un derecho con un carácter bifronte, porque sus titulares son las personas físicas consideradas en su dimensión individual y colectiva como miembros de un determinado grupo social. Nos encontramos ante un derecho de disfrute de un bien jurídico colectivo no sólo personalísimo, sino también colectivo ${ }^{88}$.

Por su parte, la jurisprudencia sostiene que:

La especial y decidida protección del medio ambiente por parte del artículo 45 de la Constitución Española, y el carácter amplio, difuso y colectivo de los intereses y beneficios que con su protección reportan a la misma sociedad - como utilidad substancial para la misma en su conjunto- nos obliga a configurar un ámbito de legitimación en esta materia, en el que las asociaciones como la recurrente debemos considerarlas como investidas de un especial interés legítimo colectivo, que nos deben conducir a entender que las mismas, con la impugnación de

\footnotetext{
${ }^{85}$ Real (1994), p. 320.

${ }^{86}$ Figueruelo (2005), p.12.

${ }^{87}$ Canosa (2006), p.181.

${ }^{88}$ Figueruelo (2005), p.14.
} 
decisiones medioambientales como las de autos, no están ejerciendo exclusivamente una defensa de la legalidad vigente, sino que están actuando en defensa de unos intereses colectivos (.... ${ }^{89}$.

En suma, sin perjuicio que la constitución aborda la protección del medio ambiente como un principio rector de la política social, la doctrina y jurisprudencia española, ha construido que la materia regulada en el artículo 45 de la constitución, para efectos de su protección, puede considerarse como un interés colectivo.

\subsubsection{Mecanismos que garanticen el derecho a un medio ambiente sano}

Al considerarse la protección del medio ambiente como un principio rector de la política social y económica y no un derecho, ésta queda excluida del recurso de inconstitucionalidad y del recurso de amparo establecidos en el artículo 161 № 1 letra a) y b) de la Constitución, respectivamente, aplicables para la protección de derechos fundamentales.

Por su parte, el numeral 3, del artículo 53 de la Constitución, señala que

el reconocimiento, el respeto y la protección de los principios reconocidos en el Capítulo III donde se encuentra el medio ambiente y la calidad de vida - informarán la legislación positiva, la práctica judicial y la actuación de los poderes públicos. Sólo podrán ser alegados ante la Jurisdicción ordinaria de acuerdo con lo que dispongan las leyes que lo desarrollen.

En doctrina se ha sostenido que respecto de la protección de lo dispuesto en el artículo 45 de la Constitución:

La línea de separación que distancia a los principios rectores de los genuinos derechos fundamentales se hace bastante más tenue. Por ello, se ha afirmado que estamos en presencia de un derecho subjetivo, de diversa caracterización. Así se ha destacado su naturaleza constitucional y su configuración legal que posibilita la protección judicial ordinaria. (...) No obstante resulta evidente que del enunciado del artículo 45 CE no se deduce un contenido esencial ni tampoco un reconocimiento jurídico de su invocación ante los tribunales ${ }^{90}$.

Por su parte la jurisprudencia ${ }^{91}$, con el propósito de otorgar una protección más robusta al medio ambiente, ha vinculado dicho principio con el derecho a la intimidad y a la integridad física y moral, los cuales corresponden a derechos fundamentales, cuya protección se puede realizar mediante el recurso de inconstitucionalidad y amparo.

Así, mediante sentencia de fecha 9 de diciembre de 1994, el Tribunal Europeo de Derechos Humanos en el caso "López Ostra con España” que, con motivo de emisión de olores, ruidos y

\footnotetext{
${ }^{89}$ Tercera Sala de lo Contencioso - Administrativo del Tribunal Supremo, Rol № STS 905/2007, de 25 de junio de 2008.

${ }^{90}$ Pérez (2017), p. 958.

${ }^{91}$ Galindo (2010).
} 
humos contaminantes causado por una planta de tratamiento de residuos sólidos y líquidos situado a pocos metros del domicilio de la recurrente, estableció que "el Estado no tuvo éxito en conseguir un equilibrio adecuado entre el interés del bienestar económico de la ciudad -el de tener una planta de tratamiento de residuos - y el disfrute efectivo de la recurrente de su derecho al respeto a su domicilio y a su vida privada y familiar". Por otro lado, el Tribunal Constitucional afirma que

[...] será ilegal toda pasividad de la Administración que tolere que se excedan los límites fijados en la ordenanza y será contraria al art. $45 \mathrm{CE}$ la inactividad prolongada de la que derive una seria degradación medioambiental de esa zona, pero sólo serán materia de un recurso de amparo aquellas omisiones que se traduzcan en la lesión de un derecho fundamental de los invocados ${ }^{92}$.

En consecuencia, al ser considerada la protección del medio ambiente como un principio rector de la política social y económica dentro de la Constitución, dicha materia queda excluida de los mecanismos de protección asociado a los derechos fundamentales, esto es recurso de inconstitucionalidad y amparo, sin embargo la jurisprudencia, al vincular esta materia con la violación de algún derecho fundamental, ha hecho aplicable, en forma indirecta, dichos recursos a la protección del medio ambiente.

\subsubsection{Carácter antropocéntrico o ecocéntrico del derecho}

La protección del medio ambiente en la Constitución española en el artículo 45 instaura el derecho de disfrutar de un medio ambiente adecuado para el desarrollo de la persona, que tiene un carácter netamente antropocéntrico. Sin embargo, esta visión se encuentra morigerada por el deber general de conservarlo.

En este sentido, se ha producido una discusión sobre este tema, ya que para algunos, la visión del medio ambiente que emerge de la Constitución corresponde a una síntesis del carácter antropocéntrico y ecocéntrico “(...) si en parte trapela una concepción antropocéntrica del ambiente, no falta la consideración del ambiente en sí, como primero beneficiario de medidas actas a preservarlo"93. Otros si bien reconocen el carácter dual de la redacción del artículo 45, señalan que dicho tratamiento "se reconduce hacia el desarrollo de la persona, lo que denota un carácter eminentemente antropocéntrico." 94 . En otra línea se ha señalado que "el carácter antropocéntrico que se implementa en la Constitución contiene un matiz moderado, lo cual

\footnotetext{
${ }^{92}$ Tribunal Constitucional de España, Rol № STS 150/2011, de 26 de octubre de 2011.

${ }_{93}$ Mangaro (2017), p.330.

${ }^{94}$ Figueroa (2008).
} 
amplía su campo de acción (...) al incluir en su interior referencias a los recursos naturales y al equilibrio ecológico, pero también a la calidad de vida"95.

El Tribunal Constitucional, al respecto ha sostenido que "el ambiente, por otra parte, es un concepto esencialmente antropocéntrico y relativo. No hay ni puede haber una idea abstracta, intemporal y utópica del medio, fuera del tiempo y del espacio. Es siempre una concepción concreta, perteneciente al hoy y operante aquí". Además, afirma que "se configura un derecho de todos a disfrutarlo y un deber de conservación que pesa sobre todos, más un mandato a los poderes públicos para la protección"96.

No obstante, la discusión doctrinaria y lo sentenciado por el Tribunal Constitucional, además, de sujetarse el medio ambiente adecuado al disfrute del ser humano, se debe enfatizar que la protección del medio ambiente en la Constitución española ha quedado establecida como un principio y no como un derecho, que no cuenta con una tutela directa, situación que permite concluir que prima el carácter antropocéntrico.

\subsubsection{Inclusión de modelo de desarrollo sostenible}

La Constitución española no considera dentro de su texto, en forma expresa, el modelo de desarrollo sostenible. No obstante, de su articulado, a modo de interpretación, se podría sostener lo contrario.

En este sentido, el artículo 40 señala que "los poderes públicos promoverán las condiciones favorables para el progreso social y económico y para una distribución de la renta regional y personal más equitativa, en el marco de una política de estabilidad económica"; por su parte el numeral 2 del artículo 45, estipula que "los poderes públicos velarán por la utilización racional de todos los recursos naturales con el fin de proteger y mejorar la calidad de la vida y defender y restaurar el medio ambiente, apoyándose en la indispensable solidaridad colectiva". Ambas disposiciones corresponden al Capítulo III del Título I, referido a los principios rectores de la política social y económica, razón por la cual no debería existir una primacía de uno sobre el otro, sino que debiese existir una aplicación coordinada de ambos principios y contar con un sistema que abogara por un modelo de desarrollo sostenible.

95 Ochoa (2014), p.270.

96 Tribunal Constitucional de España, Rol № STS 102/1995, de 31 de julio de 1995. 
En esta línea el Tribunal Constitucional, afirma que

\begin{abstract}
se configura un derecho de todos a disfrutarlo y un deber de conservación que pesa sobre todos, más un mandato a los poderes públicos para la protección (artículo $45 \mathrm{CE}$ ). En seguida, la conexión indicada se hace explícita cuando se encomienda a los Poderes Públicos la función de impulsar y desarrollar se dice, la actividad económica y mejorar así el nivel de vida, ingrediente de la calidad si no sinónimo, con una referencia directa a ciertos recursos (la agricultura, la ganadería, la pesca) y a algunos espacios naturales (zonas de montaña) (artículo $130 \mathrm{CE}$ ), lo que nos ha llevado a resaltar la necesidad de compatibilizar y armonizar ambos, el desarrollo con el medio ambiente (STC 64/1982). Se trata en definitiva del «desarrollo sostenible», equilibrado y racional, que no olvida a las generaciones futuras $(\ldots)^{97}$.
\end{abstract}

\title{
4.4.6. Consagración de otros derechos relacionados con el Medio Ambiente
}

Dentro de los otros derechos que contempla la Constitución española relacionados con esta temática, cabe destacar, el artículo 54 que establece la figura del "Defensor del Pueblo", que tiene como objetivo la defensa de los derechos establecidos en el Título primero de la Constitución, dentro de los que se encuentra el artículo 45, referido al medio ambiente y la calidad de vida. El texto constitucional estipula que una ley orgánica regulará la institución del Defensor del Pueblo, la cual fue dictada, con fecha 19 de noviembre de 2015, prescribiendo que dicha institución gozará de independencia (no estará sujeto a mandato imperativo alguno, no recibirá instrucciones de autoridad y desempeñará sus funciones con autonomía).

Por su parte, en el Capítulo III de la Constitución, se instaura la figura de las comunidades autónomas, correspondiente a una prerrogativa que tienen las provincias limítrofes, los territorios insulares y las provincias regionales con entidad histórica, para constituir autogobiernos. El artículo 148 regula las competencias que pueden tener estas comunidades, dentro de las que se encuentra la gestión en materia de protección al medio ambiente; más adelante, el artículo 149 dispone que sin perjuicio que el estado es competente para legislar sobre la protección del medio ambiente, se reconoce a la comunidad autónoma la facultad de establecer normas adicionales de protección, como legislación sobre montes, aprovechamientos forestales y vías pecuarias.

\section{Conclusiones y recomendaciones}

Del análisis del presente documento se puede observar que la CPR tiene ciertas deficiencias para lograr una efectiva protección del medio ambiente, las cuales derivan de no haberlo

${ }_{97}$ Tribunal Constitucional de España, Rol № STS 102/1995, de 31 de julio de 1995. 
consagrado como un principio en las bases de la institucionalidad, de la técnica legislativa utilizada al redactar el derecho fundamental a un medio ambiente libre de contaminación, de las limitaciones para ejercer dicho derecho, y de algunos aspectos que han sido omitidos al momento de su redacción. En este contexto, cabe señalar que la jurisprudencia ha realizado interpretaciones orientadas a fortalecer la protección del medio ambiente, sin embargo, en nuestra opinión, es el texto constitucional el que debería establecer un estatuto suficiente de protección y no quedar aquello entregado al criterio jurisprudencial.

La importancia en cuanto a la omisión del medio ambiente dentro de las bases de la institucionalidad radica no solo en su importancia valórica como declaración de los principios del país, sino que a su vez en su relevancia práctica, ya que lo que se establezca en este capítulo es el prisma bajo el cual se interpretará y aplicará la Carta Fundamental.

En este sentido la experiencia de Colombia como la de Ecuador de incluir dentro del primer capítulo la protección del medio ambiente, además de estipularlo como un derecho humano, es un claro ejemplo de buenas prácticas a seguir. Así, en Colombia se optó por integrar en el título I sobre principios fundamentales la obligación del Estado y las personas de proteger las riquezas culturales y naturales de la nación, mientras que, en Ecuador en el capítulo primero sobre principios de aplicación de los derechos, señala que la naturaleza será sujeto de aquellos derechos que le reconozca la Constitución.

En este orden de ideas, a nuestro juicio el medio ambiente, debiese ser tratado como un principio rector dentro de las bases de la institucionalidad, permitiendo caracterizar y concebir a un Estado que contemple la problemática ambiental en cada una de sus decisiones y actuaciones, como complemento al derecho fundamental relacionado con esta materia.

Por su parte, en cuanto a la técnica legislativa utilizada podemos observar una serie de problemas relacionados con el concepto de contaminación, que restringe el ámbito de protección del derecho fundamental sólo a los casos en que existe una superación de un umbral legal. Así, se puede observar que salvo España que utiliza la voz "medio ambiente adecuado", la mayoría de las constituciones utilizaron la fórmula de medio ambiente sano como objeto de protección, yendo un poco más allá las de Costa Rica y Ecuador al agregar a la protección del medio ambiente sano, el concepto de ecológicamente equilibrado. En este sentido, en nuestra opinión la nueva constitución de Chile debería tener una redacción similar a esta última, ya que permite, una protección mucho más amplia del medio ambiente, incluyendo hipótesis de 
protección que en la CPR chilena actual no se permiten, y salvando las deficiencias actuales de la técnica legislativa utilizada. Por otro lado, la posibilidad de restringir o limitar el concepto de medio ambiente sano como se hizo con la contaminación en la Ley N⒚300, tendría muchas dificultades, considerando que tanto tratados internacionales, organismos internacionales y la experiencia comparada utiliza este concepto de una forma más amplia que el término contaminación.

Otro problema que ha generado la redacción del artículo $19 \mathrm{~N}^{\circ} 8$ tiene relación con el sesgo antropocéntrico y el estrecho vínculo con el derecho a la vida. En este punto, a nuestro juicio definitivamente debería ser parte del debate constitucional la inclusión de un modelo biocéntrico o ecocéntrico como el consagrado en Ecuador que otorga derechos a la naturaleza, lo cual no sólo significaría una declaración valórica importante, sino que ampliaría la titularidad de la acción y permitiría ejercerla incluso en los casos en que no se ven afectados los seres humanos como consecuencia de la afectación del medio ambiente.

Sumamente ligado a lo anterior, tenemos la concepción del derecho al medio ambiente como individual o colectivo, distinción relevante, dado que se relaciona directamente con los legitimados activos para accionar por su defensa y por los mecanismos de protección constitucional aplicables al efecto. Como fue mencionado en este trabajo, en el caso de nuestro actual texto constitucional, se requiere la figura de un afectado para poder accionar de protección por vulneraciones al derecho a vivir en un medio ambiente libre de contaminación.

En el análisis comparado realizado, se pudo observar que las constituciones de Colombia, Costa Rica y Ecuador, consagran el derecho al medio ambiente, como un derecho colectivo, permitiendo que no sea solamente el directamente afectado quien accione por la protección de dicho derecho. Adicionalmente, en el caso de Ecuador, se establece a la naturaleza como un sujeto de derechos, cuya legitimidad pertenece a "cualquier persona". En virtud de lo anterior, consideramos que el derecho al medio ambiente en un nuevo texto constitucional debe ser consagrado como un derecho colectivo, con una legitimidad amplia para poder accionar por su defensa. En esta línea, creemos necesario que sean titulares de este derecho tanto personas naturales como jurídicas y que la afectación del medio ambiente no requiera la figura de un afectado para poder accionar en su favor, sea o no sean otorgados derechos a la naturaleza en la nueva Constitución. 
Por su parte, en cuanto a la acción de protección en sí misma, se pudo examinar en este trabajo que en nuestra CPR actual ésta es más limitada que los otros derechos que se contemplan en esta acción, debido a la improcedencia frente actos arbitrarios, la necesidad de que sea imputable a una autoridad o persona determinada, y el requisito que el derecho sea afectado lo cual hace discutible la posibilidad de presentar la acción ante una amenaza. Al respecto, en nuestra opinión es de suma importancia que los derechos que se consagren para la protección del medio ambiente en el nuevo texto constitucional tengan los mismos requisitos que los otros derechos fundamentales o incluso puedan llegar a ser más amplios que en los otros casos, como sucede en el requisito de la legitimación activa antes mencionado.

En otro orden de ideas, con relación a la tutela de preservación de la naturaleza del Estado consagrada en el texto constitucional actual, a pesar de que las constituciones analizadas han utilizado el mismo concepto, en nuestra opinión se debería apuntar a utilizar el término medio ambiente al contener una definición más amplia y a ser más precisos en el rol que debe tener el Estado en esta tarea, el cual debe ser independiente del derecho fundamental.

Respecto a los vacíos legales que se han evidenciado en este trabajo al analizar otros derechos o principios consagrados en las constituciones examinadas, el caso de Ecuador nos muestra que es posible y a su vez necesario incluir normas de mitigación y adaptabilidad al cambio climático, las cuales son de suma importancia considerando la vulnerabilidad de este país a este fenómeno ${ }^{98}$. Por lo tanto, el debate constitucional debe contemplar este aspecto para ser incluido dentro de la carta de derechos fundamentales protegidos por nuestro país.

Por otro lado, para equiparar las diferencias que pueden existir entre las partes en un conflicto ambiental, en la Constitución de Colombia se establece la figura de un "Procurador General de la Nación" quién dentro de sus funciones cuenta con la de defender intereses colectivos, como el medio ambiente sano. Junto con ello, tanto el caso colombiano, como el ecuatoriano y español, consagran la figura de un "Defensor del Pueblo"; que dentro de sus funciones se encuentran las de proteger los principios y derechos ligados al medio ambiente. De esta forma, en nuestra opinión, atendiendo el contexto nacional, consideramos que la técnica legislativa que se utilice en una nueva Constitución debe contemplar, la creación de un Defensor del Pueblo y que, dentro de otras competencias, se contemplen las materias ambientales.

${ }^{98}$ OIM (2017), p. 60. 
Finalmente, sin perjuicio del desarrollo jurisprudencial en esta materia, el desarrollo económico sin considerar al medio ambiente ha sido una de las grandes causas de los problemas medio ambientales que se han observado en Chile, por lo que la inclusión de un modelo de desarrollo sustentable se hace sumamente necesaria. La experiencia de Colombia y Ecuador que establecen texto expreso en este sentido es un gran ejemplo de una buena práctica en esta materia, sin embargo, la fórmula utilizada por Ecuador de consagrar el modelo de desarrollo sostenible en el primer capítulo es a nuestro parecer a lo que se debería apuntar en nuestro país, debido a que dicho concepto sería parte de los criterios para interpretar las otras disposiciones de la nueva CPR.

Así las cosas, hemos podido observar que la CPR actual de nuestro país, contiene muchos aspectos en los cuales podría avanzar para tener una protección del medio ambiente más robusta, siendo la experiencia de otros países de suma relevancia para generar las mejoras necesarias en esta materia.

\section{Bibliografía citada}

Abú, Nayid, González, Angélica y Londoño, Beatriz (2010): El medio ambiente sano, un derecho de todos. Grupo de acciones públicas. (Bogotá, Universidad del Rosario).

Actas de la Comisión Ortúzar (1976): Sesión № 186 de 9 de marzo de 1976. [Fecha de consulta: 17 de diciembre de 2019] [Disponible en: https://bit.ly/3pjRe0Y]

Aguilar Cavallo, Gonzalo (2015): "El derecho a vivir en un medio ambiente libre de contaminación: deficiencias y desafíos en un contexto de cambio constitucional”. En JURIS, Río Grande (v.23), pp. 9-39.

Aguilar Cavallo, Gonzalo (2016):"Las Deficiencias de la formula “Derecho a vivir en un medio ambiente libre de contaminación" en la Constitución Chilena y algunas propuestas para su revisión”, en Estudios Constitucionales(Año 14, № 2). pp. 365-415.

Atria, Fernando (2015): La Constitución Tramposa (Santiago, Lom Ediciones).

Ayora Jara, María Isabel (2014): "Los Derechos de la Naturaleza y los Mecanismos Jurisdiccionales de Tutela en la Constitución de Ecuador del 2008”, tesis para optar a grado 
de Magister Derecho Mención Derecho Constitucional (Quito, Universidad Andina Simón Bolivar).

Bedón Garzón, René Patricio (2017): “Aplicación de los Derechos de la Naturaleza en Ecuador”, en Veredas do Direito: Direito Ambiental e Desenvolvimento Sustentável (v. 14, n. 28, jun. 2017). pp. 13-32.

Bermúdez Soto, Jorge (2000):“El Derecho a Vivir en una Medio Ambiente Libre de Contaminación", en Revista de Derecho de la Universidad Católica de Valparaíso (XXI). pp. 925.

(2014): Fundamentos de Derecho Ambiental (Valparaíso, Ediciones Universitarias de Valparaíso).

Bordalí Salamanca, Andrés (1998): “Titularidad y legitimación activa sobre el medio ambiente en el derecho chileno" en Revista de Derecho, (Vol. 9, N 1), pp. 43-64.

Bórquez Yungue, José Manuel (1993): "Introducción al Derecho Ambiental Chileno y Comparado" (Santiago de Chile, Editorial Jurídica de Chile).

Bustamante Romo Leroux, Francisco (2016): "Los derechos de la naturaleza en la jurisprudencia constitucional ecuatoriana", en Memorias - 14ํㅡㄹ Encuentro Internacional de Derecho Ambiental - Capítulo II - La Sustentabilidad como Derecho Humano, complemento o antítesis del Derecho a un Medio Ambiente Sano (IJ-XCIV-945). [fecha de consulta: 13 de febrero 2020] [Disponible en: https://bit.ly/2S9nLLa].

Cabrera Medaglia, Jorge (2016): "La sentencias de la Sala Constitucional y su impacto en el origen y evolución del Derecho Constitucional Ambiental en Costa Rica”, en Peña Chacón, Mario “El Derecho al Medio Ambiente en La Constitución Política, Alcances y Límites” (San José, Editorial Isolma S.A).pp. 63-86.

Canosa, Raúl (2006): “¿Existe un verdadero derecho constitucional a disfrutar del medio ambiente?" en Anuario de Derechos Humanos, Nueva Época (Año 2006, № 7), pp.151-215.

Cea Egaña, José Luis (2002): Derecho Constitucional Chileno (Santiago, Chile, Ediciones Universidad Católica de Chile), Tomo I. 
Comisión Económica para América Latina y el Caribe (2012): La Economía del Cambio Climático en Chile. Síntesis. Colección Documentos de Proyectos (Santiago, CEPAL).

Durán Medina, Valentina (2005): “Caso "CELCO": Un fallo controvertido de la Excma.Corte Suprema", en Revista de Derecho Ambiental (Núm. 2), pp. 253-275.

Figueruelo, Ángela (2005): "Protección constitucional del medio ambiente en España y Europa", en Revista de Criterio Jurídico (Año 2005, №5), pp. 9-29.

Figueroa, Ivo (2008): “El derecho a un medio ambiente adecuado en la Constitución Española de 1978", en Revista Electrónica de Derecho Ambiental (Año 2008, №17).

FIMA (2018): Discusión sobre Medio Ambiente en el marco de una nueva Constitución (Santiago de Chile).

Galdámez Zelada, Liliana (2017): “Medio Ambiente, Constitución y Tratados en Chile”. En Boletín Mexicano de Derecho Comparado nueva serie (año XLX, núm. 148), pp. 113-144.

(2018): “Constitución y medio ambiente”, en Revista de Derecho Ambiental, (09), pp. 72-92.

Garita Navarro, José y Jiménez Sanabria, Santiago (2016):"Acciones colectivas, difusas y populares para la defensa del ambiente”, en Peña Chacón, Mario “El Derecho al Medio Ambiente en La Constitución Política, Alcances y Límites" (San José, Editorial Isolma S.A), pp.167-258.

Galindo, Fernando (2010): "Sinópsis del artículo 45 de la Constitución española" [fecha de consulta: 3 de enero de 2020] [Disponible en: https://bit.ly/3f4p9ak].

Historia de la Ley $\mathrm{N}^{\circ} 20.050$, publicada en el Diario Oficial el 26 de agosto de 2005. [fecha de consulta: 21 de julio de 2020] [Disponible en página web: https://bit.ly/3cKpgqp].

Jurado Fernández, Julio (2016): “La Regulación Constitucional del Ambiente en Costa Rica”, en Peña Chacón, Mario "El Derecho al Medio Ambiente en La Constitución Política, Alcances y Límites" (San José, Editorial Isolma S.A). pp. 39-62. 
Lucas Garín, Andrea (2007):“El derecho a vivir en un medio ambiente libre de contaminación: su recepción en la Constitución Chilena reformada”, en Revista de Derecho Público (Vol. 69, Tomo I, Primera Sección, Comisión de Derecho Constitucional). pp. 233-246.

Mangaro, Marta (2017) "El desarrollo del derecho a un ambiente sano en la perspectiva constitucional española e italiana", en Revista Jurídica de los Derechos Sociales (Año 2017, №7), pp. 321-340.

Melón Velásquez, Herber (2016): La protección Constitucional del medio ambiente sano en Colombia". (Salamanca, Ediciones Universidad de Salamanca).

Mesa García, Luis (2001): El derecho a un medio ambiente sano como derecho humano, sus principios rectores y constitucionalización. (Medellín, Universidad Autónoma Latinoamericana).

Naciones Unidas, Asamblea General (2010): “Resolución 64/236. Ejecución del Programa 21 y del Plan para su ulterior ejecución y aplicación de los resultados de la Cumbre Mundial sobre el desarrollo sostenible, [fecha de consulta: 2 de enero de 2020] [Disponible en página web: https://bit.ly/3ijLhQq].

Ochoa, Alejandro (2014): "Medio Ambiente como un bien jurídico protegido ¿visión antropocéntrica o ecocéntrica?", en Revista de Derecho Penal y Criminología (Año 2014, №11), pp. 253-294.

Organización Internacional para las Migraciones (2017): Migraciones, ambiente y cambio climático. Estudios de casos en américa del sur. Cuadernos Migratorios $N^{\circ} 8$ (Buenos Aires, OIM).

Ossandón Rosales, Jorge (2015) “Garantías fundamentales de las personas jurídicas. ¿Titulares del derecho a vivir en un medio ambiente libre de contaminación?", en Revista de Derecho Público (Vol. 83, $2^{\circ}$ semestre), pp. 123-139.

Pérez, Nicolás (2017) “El Derecho - Deber de Protección del Medio Ambiente”, en Revista de Derecho Político (Año 2017, №100), pp. 949-986.

Real, Gabriel (1994) “El Medio Ambiente en la Constitución Española de 1978”, en Revista Jurídica de Medio Ambiente (Año 1994, №4), pp.319-328. 
Sagot Rodríguez, Álvaro (2016): "El Derecho Constitucional Ambiental Costarricense en momentos de un Neoconstitucionalismo con enfoque Biocéntrico", en Peña Chacón, Mario "El Derecho al Medio Ambiente en La Constitución Política, Alcances y Límites" (San José, Editorial Isolma S.A). pp. 87-132.

Velázques-Gutiérrez, José Manuel (2014): “Derechos de la Madre Tierra y Buen Vivir”, en Entramado (Vol. 10, No., 2014 (enero-junio)). pp. 220-238.

Varela, Joaquín (2003) "La Constitución de 1978 en la historia constitucional española”, en Revista Española de Derecho Constitucional (Año 23, №69), pp. 42-48.

Vargas Miranda, Rafael (2007): Instituciones de derecho ambiental : El recurso de protección ambiental (Santiago, Editorial Metropolitana).

\section{Jurisprudencia citada}

Tribunal Constitucional de España: Gobierno Vasco, la Junta de Andalucía, el Gobierno de Canarias, la Generalidad de Cataluña, la Junta de Galicia y el Parlamento de Cataluña, contra la Ley 4/1989, de 27 de marzo, de Conservación de los Espacios Naturales y de la Flora y Fauna Silvestres (recurso de constitucionalidad), de 31 de julio de 1995 en Corte Constitucional Colombiana. [Disponible en: https://bit.ly/3gdlAOy]. [fecha de consulta: 6 de marzo 2020].

Corte Constitucional Colombiana: Escobar y otros con Alcalde del Distrito Turístico, Cultural e Histórico de Santa Marta y otros, de 16 de septiembre de 1997 en Corte Constitucional Colombiana. [Disponible en: https://bit.ly/3vRlymk]. [fecha de consulta: 25 de febrero 2020].

Corte Constitucional Colombiana: Macías con Wiesner, de 1 de abril de 1998. [Disponible en: https://bit.ly/3g2ISGM]. [fecha de consulta: 25 de febrero 2020].

Corte Suprema de Costa Rica: Guido y Machore con Procurador General de la República (acción de inconstitucionalidad), de 03 de julio de 2003 en Nexus.pj [Disponible en: https://bit.ly/3g8qs7R]. [fecha de consulta: 13 de marzo 2020]. 
Tribunal Constitucional de Chile: Becker, Estay y otros con Ministerio de la Secretaría General de la Presidencia (Requerimiento de inconstitucionalidad), Rol № 577-06Becker, 26 de abril de 2007.

Tribunal Constitucional de Ecuador: Valencia y otros con Ministerio del Medio Ambiente (acción de amparo constitucional), de 19 de septiembre de 2007 en Derecho Ecuador [Disponible en: https://bit.ly/3z5T75V]. [fecha de consulta: 01 de marzo 2020].

Tribunal Supremo de España: Asociación Gecen con Administración General del Estado (recurso de casación), Tercera Sala de lo Contencioso - Administrativo del Tribunal Supremo, del 25 de junio de 2008 [Disponible en: https://bit.ly/34QAUeK]. [fecha de consulta: 26 de febrero 2020].

Corte Suprema de Costa Rica: Araya con Ministerio de la Presidencia y otros (recurso de amparo constitucional), de 16 de abril de 2010 en Nexus.pj [Disponible en: https://bit.ly/3ceUNAb]. [fecha de consulta: 13 de marzo 2020].

Tribunal Constitucional de Ecuador: Vargas con Andrade y otros (acción pública de inconstitucionalidad), de 15 de julio de 2010 en Megalex [Disponible en: https://bit.ly/3gFu1T2]. [fecha de consulta: 22 de febrero de 2020].

Corte Suprema Chile: Gonzalo Lira y otros con Ilustre Municipalidad de Temuco (apelación recurso de protección), Rol º 4.690/2010, de 15 de agosto de 2010.

Tribunal Constitucional de Chile: Requerimiento presentado por 17 Senadores respecto de la inconstitucionalidad del Convenio Internacional para la Protección de Obtenciones Vegetales (UPOV-91) (requerimiento inconstitucionalidad), Rol № 1988-11, de 24 de junio de 2011.

Corte Constitucional Colombiana: Montealegre Lynett (acción de inconstitucionalidad), de 24 de agosto de 2011 en Corte Constitucional [Disponible en: https://bit.ly/3ge5Vih]. [fecha de consulta: 26 de febrero 2020].

Tribunal Constitucional de España: Cuenca con Sentencia de la Sección Tercera de la Sala de lo Contencioso- Administrativo del Tribunal Superior de Justicia de la Comunidad Valenciana de 20 de junio de 2003, de 26 de octubre de 2011 [Disponible en: https://bit.ly/3ifczXV]. [fecha de consulta: 13 de marzo 2020]. 
Corte Suprema de Chile: González Cid Mario con Industrias de Madera Rarinco, Rol ํㅜ 11. 845/2011 (apelación recurso de protección), de 22 de enero de 2012.

Corte Suprema Chile: Corporación Fiscalía del Medio Ambiente con Servicio de Evaluación Ambiental (apelación recurso de protección), Rol № 2463-2012, de 11 de mayo de 2012.

Corte Suprema Chile: Confederación Nacional de Federaciones de Pescadores Artesanales de Chile con Comisión de Evaluación VIII Región (apelación recurso de protección), Rol №31412012, de 15 de junio de 2012.

Corte Suprema Chile: Manuel Rocco Hidalgo y otros con Directora Regional (S) Servicio de Evaluación Ambienta e Intendente (S) III Región Atacama (apelación recurso de protección), Rol N 1960-2012, de 27 de agosto de 2012.

Corte Suprema Chile: Condominio Archipiélago Las Antillas con Empresa Aguas del Altiplano (apelación recurso de protección), Rol N 7041-2012 , 25 de noviembre de 2012.

Corte de Apelaciones de Valparaíso: Grupo de Acción Ecológica Chinchimén con Inmobiliaria Laderas Lado Mar S.A. y otros (recurso de protección), Rol № 1670-2012 , 28 de marzo de 2013.

Corte Suprema Chile: Agrícola María Elba Herrera Limitada Ltda. con Sociedad Patagonia Fresh S.A. y otros (apelación recurso de protección), Rol № 7844-2013, de 25 de noviembre de 2013.

Corte Suprema Chile: Rendón Escobar Luis Mariano y otros con Gabriel Ruiz Tagle (apelación de recurso de protección), Rol N 7.677-2013, de 6 de enero de 2014.

Corte Suprema Chile: Consejo de Defensa del Estado con Molibdenos y Metales S.A. y Empresa de F.F. del Estado, Rol No 15.996-2013, de 31 de agosto de 2014.

Corte Suprema Chile: Confederación Nacional de Federaciones de Pescadores Artesanales de Chile con Empresa Nacional de Electricidad S.A. (apelación de recurso de protección), Rol N ${ }^{\circ}$ 23.622/2014, de 26 de noviembre de 2014.

Corte Constitucional Colombiana: Fundación para la defensa del interés público con sala Civil y de Familia del Tribunal Superior del Distrito Judicial de Cartagena, de 20 de febrero de 2015 
en: Corte Constitucional Colombiana [Disponible en: https://bit.ly/3uT4ElZ]. [fecha de consulta: 26 de febrero 2020].

Tribunal Constitucional de Chile: Molinera del Norte S.A. con Ilustre Municipalidad de Antofagasta (requerimiento de inaplicabilidad por inconstitucionalidad), Rol № 2643-14, de 27 de enero de 2015.

Tribunal Constitucional de Chile: Curtidos Bas S.A. con Ilustre Municipalidad de San Joaquín (requerimiento de inaplicabilidad por inconstitucionalidad), Rol № 2684-14, de 10 de septiembre de 2015.

Contraloría General de la República (2016): 15 de enero de 2016 (dictamen).

Corte Constitucional Colombiana: Centro de estudios para la justicia social "Tierra Digna" con la Presidencia de la República y otros (acción de tutela), de 10 de noviembre de 2016 en Corte Constitucional Colombiana [Disponible en: https://bit.ly/3g9VBHR]. [fecha de consulta: 26 de febrero 2020].

Corte Constitucional Colombiana: Revisión oficiosa de constitucionalidad Sentencia C-644/17, de 18 de octubre de 2017 en Corte Constitucional Colombiana [Disponible en: https://bit.ly/34LnUHt]. [fecha de consulta: 26 de febrero 2020].

Corte Suprema: Matías Ramírez Pascal con Constructora FV S.A. (apelación recurso de protección), Rol N 45.059-2017, de 13 de marzo de 2018.

Corte Constitucional Colombiana: Agudelo con Juzgado Segundo Civil del Circuito de Fusagasugá y Tribunal Superior del Distrito Judicial de Cundinamarca (acción de tutela), de 24 de agosto de 2018 en: Corte Constitucional Colombiana [Disponible en: https://bit.ly/2S1W3jB]. [fecha de consulta: 26 de febrero 2020].

Corte Suprema Chile: Díaz con Seremi Salud Región de Arica y Parinacota (apelación recurso de protección), Rol N 5.473/2019, de 16 de abril de 2019.

Corte Suprema Chile: Gutiérrez con Inmobiliaria Progreso Ltda. (apelación recurso de protección), Rol N².515/2019, de 23 de mayo de 2019. 
Corte Suprema Chile: Fundación Yarur Bacuñán con Constructora Vimac Spa. (apelación de recurso de protección), Rol № 12.808-2019, de 5 de junio de 2019.

Corte de Apelaciones de Valparaíso: Francisco Chahuán Chahuán contra Empresa Nacional de Petróleos, ENAP S.A. (recurso de protección), Rol N 5888-2019, de 28 de mayo de 2019. 